\title{
Redefining the Witness: \\ CSI and Law \& Order as Narratives of Surveillance
}

\author{
By: Sanam Navid
}

\section{A thesis submitted in partial fulfillment of the requirements for the degree of Master of Arts Communication}

Sanam Navid 0 2007. All Rights Reserved. 


$\begin{array}{ll}\begin{array}{l}\text { Library and } \\ \text { Archives Canada }\end{array} & \begin{array}{l}\text { Bibliothèque et } \\ \text { Archives Canada }\end{array} \\ \begin{array}{l}\text { Published Heritage } \\ \text { Branch }\end{array} & \begin{array}{l}\text { Direction du } \\ \text { Patrimoine de l'édition }\end{array} \\ \begin{array}{l}\text { 395 Wellington Street } \\ \text { Ottawa ON K1A ON4 }\end{array} & \begin{array}{l}\text { 395, rue Wellington } \\ \text { Ottawa ON K1A ON4 } \\ \text { Canada }\end{array}\end{array}$

Your file Votre référence ISBN: 978-0-494-33753-0 Our file Notre référence ISBN: 978-0-494-33753-0

NOTICE:

The author has granted a nonexclusive license allowing Library and Archives Canada to reproduce, publish, archive, preserve, conserve, communicate to the public by telecommunication or on the Internet, loan, distribute and sell theses worldwide, for commercial or noncommercial purposes, in microform, paper, electronic and/or any other formats.

The author retains copyright ownership and moral rights in this thesis. Neither the thesis nor substantial extracts from it may be printed or otherwise reproduced without the author's permission.
AVIS:

L'auteur a accordé une licence non exclusive permettant à la Bibliothèque et Archives Canada de reproduire, publier, archiver, sauvegarder, conserver, transmettre au public par télécommunication ou par l'Internet, prêter, distribuer et vendre des thèses partout dans le monde, à des fins commerciales ou autres, sur support microforme, papier, électronique et/ou autres formats.

L'auteur conserve la propriété du droit d'auteur et des droits moraux qui protège cette thèse. $\mathrm{Ni}$ la thèse ni des extraits substantiels de celle-ci ne doivent être imprimés ou autrement reproduits sans son autorisation.
In compliance with the Canadian

Privacy Act some supporting forms may have been removed from this thesis.

While these forms may be included in the document page count, their removal does not represent any loss of content from the thesis.
Conformément à la loi canadienne sur la protection de la vie privée, quelques formulaires secondaires ont été enlevés de cette thèse.

Bien que ces formulaires aient inclus dans la pagination, il n'y aura aucun contenu manquant.

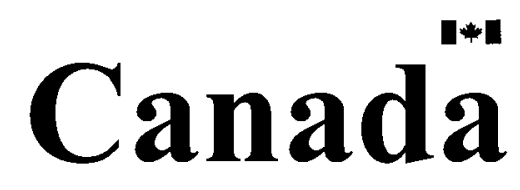




\begin{abstract}
This thesis explores the normalization of surveillance technology in today's society by analyzing the relationship between the body and technology. Turning to popular culture, the relationship is investigated through the changing nature of the role of the witness. The surveillance narratives of the Law \& Order and CSI franchises provide for a prosthetic and posthumanist understanding of the human subject in relation to witnessing, respectively. Dependent on how each franchise approaches the body, the subject, technology and the truth, the witness provides for a dialogue of enhancement, replacement, agency, neutrality, and the distinction between the embodied identity versus the digital double.
\end{abstract}




\begin{abstract}
Acknowledgements
I would like to thank Sheryl Hamilton for supporting my interest in the normalization of surveillance in today's society, coupled with my odd obsession with CSI and Law \& Order, to provide for an exciting take on the surveillance literature. You have let me grow creatively and provided me with the guidance to take my ideas and develop them. Your views, suggestions, criticisms and the little brainstorming activities that you gave me have helped guide me on this unique route to understanding our surveillance society and how popular culture's approach to the body and technology, normalizes surveillance. Your support has kept me sane throughout the process. Thank you for allowing me to be creative on this project; this is as much your accomplishment as it is mine. It was a pleasure to have you as an advisor.
\end{abstract}

Also, I couldn't have done this without the love and support of my family, especially my mother, and Vince Iacobucci, who deserves a Masters in Communication for having to listen to my academic rants and dealing with the stresses of finishing the thesis. Thank you. 


\section{Table of Contents}

$\begin{array}{ll}\text { Introduction } & 1\end{array}$

Law \& Order and CSI as Surveillance Narratives 27

The Old fashioned way: Reclaiming the human

Subject in a Post 9/11, Post-Panoptic Surveillance

Culture

Seeking Objectivity: The Posthuman Replacement of Man with Machine

Understanding the Witness in the Information Age

Appendix

Bibliography 


\section{Chapter 1}

\section{Introduction}

The two machines commune together as the polygraph reached out to embrace the subject's body with bands, tubes, and clips. The body responds lover-like to the touch, whispering secrets to the polygraph in tiny squeezes, twinges, thrills, and nudges. Both the machines are treacherous. The body, seduced by the polygraph's embrace, thoughtlessly prattles the confidences it shares with the subject's mind. The polygraph, a false and uncaring confidant, publishes the secrets it has learned on a chart to read. The subject as mind, powerless to chaperone the affair, watches helplessly as the carnal entwine of the machines produces its undoing (Hanson 1993, 93).

In this poetic description, Allen Hanson posits a striking relationship between technology and the body. The polygraph is a technological device that seeks and provides information through the relationship it forms with the body, helping in the body's disembodiment. As it breaks the confidentiality of the body/machine relationship, private concerns, secrets and information we do not intend to disclose are ascertained by the device and divulged to those who accuse, categorize and sort. The polygraph is a surveillance device which seeks and gathers information. Its ability to do so is dependent on the body's reaction to its questions; the beating of the heart allows for its invasiveness, without the subject's consent. The 'double-cross' nature of the polygraph can be seen in surveillance technology: it is a form of security, a confidante, but also an infringer of privacy. I hope to demonstrate the way in which our trust in the polygraph epitomizes our naive embrace of surveillance technologies; we overlook their deceptive nature and focus instead on the benefits that accrue through their intimate relationship with the body.

\section{What is it all about?}

We are a surveillance society. With the advent and social integration of the internet, followed by the tragic terrorist attacks of $9 / 11$, the acceleration of surveillance 
techniques to protect us against risks and uncertainties, have increased. Surveillance, mobilized through technology, is all around us. Despite the imbrications of surveillance into all areas of public life, there has been criticism of the Big Brother effect, and the way in which surveillance technologies infringe upon our right to privacy. Although Orwell's dystopic tale, Nineteen Eight-Four, now plausibly depicts the direction in which today's society is heading, the public's voice offers little resistance to surveillance. Despite scholarly and media criticism, people seem to embrace surveillance in its most invasive forms, i.e. heat imagers, biometrics, and Radio Frequency Identification (RFID) chips. This raises the question of how is surveillance technology normalized?

This thesis seeks to understand the use of surveillance technology beyond the fear or risk framework, by looking at surveillance in popular culture. I read two different television shows as narratives of surveillance exploring, in particular, how they treat the figure of the witness. The witness serves, in different ways, as a non-threatening means of presenting the relationship between surveillance technology and the human subject. In the pursuit of the broader social goal of justice, the figure of the witness in the two popular cultural surveillance narratives of the Law \& Order and CSI franchises, together serve to demystify and contain the threat to the citizen of surveillance technology.

\section{From Foucault to the Post-Foucauldian Understanding of Surveillance}

One of the primary ways in which we come to understand and experience surveillance is through an array of technologies and their relationship to our bodies. This complicated relationship between technology and the impact it has on the late modern body requires us to focus on more recent theoretical work. The primary model of 
surveillance is Jeremy Bentham's panoptic prison, a metaphor that Michel Foucault adopts in his notion of the disciplinary society, and whose theories have been borrowed and adopted by others.

The Foucauldian understanding of surveillance sees the process of the disciplinary society as one where power flows from the top-down. Adopting Bentham's panoptic prison as a model of maximum visibility, Foucault theorizes that this particular mode of organizing the spatial arrangements of prisons, schools, hospitals and factories is a form of internalized disciplinary practice that causes one to act as if one is constantly being watched by authorities, even when one is not (Foucault 1977, 201). Foucault's conceptualization of the panoptic 'diagram', explains the process as the powerful few observing the many. Furthermore, he theorizes that the notion of a panopticon would “entail a particular form of power relation and restriction of behaviour" (Mills 2003, 45). Implying that power circulates, Foucault asserts that prisons, mental institutes, the State, and discourse, situate and establish people in particular power relationships (Foucault 1997, 202). He further argues that the goal of unequal power relationships, and the imperative to classify subjects as either good or bad, serves to forge the 'docile' body: mute, obedient individuals who are subjected, transformed and improved (Staples 1997, 27).

Other scholars, such as Reg Whitaker (1999), Oscar Gandy (1993) and David Lyon (2001, 2002) borrow from Foucault and further apply the panoptic theory to modern techniques that aim to discipline. Whitaker employs the panoptic model to analyse the disciplinary nature of Disneyland's architecture, while Gandy and Lyon focus on data-mining software as a form of technology that not only enables the gathering and 
storing of people's information, but also helps to categorize and sort people according to financial capacities, consumption habits and health (Gandy 1993, 4). Lyon argues against the construction and implementation of data-doubles, which he refers to as the information collected and profiled on individuals, through software, which serve as stand-ins for the subject, without their knowledge. Pinpointing the flaws of Foucault's theory for its discriminatory hierarchal characteristics, these scholars continue to conceive surveillance technology as disciplinary.

The relationship of surveillance and technology is further demonstrated in the use of such technologies as crisis management tactics targeted against the uncertainty of future threats. Geoffrey Mulgan (1991) explains the necessity of surveillance technology in the tracking of criminal suspects through phone tapping and Closed-Circuit Television (CCTV). As theorized by Ulrich Beck's (1992) risk society theory, surveillance has become a step towards protection of uncalculated risks. Clive Norris and Gary Armstrong (1990) acknowledge the risk and protectionist framework and negatively credit the media for legitimizing surveillance devices in its language of promoting and maintaining public support.

Arguing against the top-down model of surveillance, Mark Poster (1990) moves away from the 'all-seeing eye' of surveillance technology to concentrate on data gathering technology, the most elementary of which is the 'form'. A form is a structured document in which the one being surveyed is also the one who provides the information; hence the involvement of the subject is voluntary. Poster coins his concept of the 'superpanoptic', and claims that technological changes are only part of the process in the shift to a disciplined population (Poster, 93). He differentiates the superpanoptic from 
Foucault's panoptic in that Foucault was concerned with the decoding of discourse rather than the intention of a subject, whereas Poster applies this idea to the mode of information, to discover that the population now participates in its own self-constitution by normalizing the gaze of the superpanoptic (Poster, 97). His analysis thus posits databases as the most used and extensive form of technology in tracking individuals.

Similar to Poster, Thomas Mathieson (1997) approaches surveillance as disciplinary; however he tweaks the top-down assumption of surveillance theory, claiming that technology has turned the tables, allowing for a bottom-to-top concept of surveillance. Referring to the change of surveillance culture as one of 'synopticism', Mathieson claims that there is a simultaneous process of 'the many watching the few'. Mathieson accounts for the role of mass media in contemporary society and explains that personalities on television are regarded as a reliable source to guarantee the trust of the consumers, which demonstrates the extent to which the mass media possess the powerful resources necessary to discipline and control society.

Taking a post-modern approach, William Bogard (1996) criticizes the panoptic model for its perception of information technology as functioning solely through the confinement of the individual to a terminal fixed space. He proposes simulation as a better approach through which to examine the panoptic, as the Foucauldian understanding of surveillance fails to answer questions regarding the direction of social control. Bogard's idea of simulation, as the panoptic imaginary, is required in understanding the complexity of social and private life, sexuality, the military etc. Drawing upon Jean Baudrillard, Bogard proposes the 'hyper-panoptic' as a different analytical tool through which to measure a society that has extended its gaze beyond the architectural control of 
walls or fixed time and space, in other words, to a cyber-architecture within virtual time and space. Bogard takes this notion further by distinguishing between surveillance and simulation. He defines simulation as the 'strategies of the real', that which masks the absence of the real as invisible, unlike surveillance, which unmasks its presence. Bogard notes that Foucault's emphasis on the way in which asymmetrical relations of power materialize, determines that it is not only through observational mechanisms or ways they themselves are camouflaged, but also masks what surveillance tries to strip (Bogard, 21).

The relationship between surveillance and technology is approached in a different manner by Kevin Haggerty and Richard Ericson (2000), who coin the term, the surveillant assemblage. Conceptualized as a self-styled notion, enables not only the important transformation in purpose and intention of surveillance practice, but also the democratization of surveillance hierarchies, helping to explain the increasing convergence of what were once discrete systems of surveillance.

The surveillant assemblage approaches the embodiment of individuals, not with the intent to punish or control, but to break the body down into series of data flows. The introduction of 'breaks', or divisions into otherwise free-flowing phenomena, contributes to the creation of physical and cognitive spaces that capture and appropriate flows. It is not the personal identity of the embodied individual, but the actuarial or categorical profile of the collective which is of foremost concern within an assemblage. The surveillant assemblage can thus be understood as a mechanism of 'visualization', which gives rise to a cyborg flesh/technology union comprised of pure information which is only then redirected back towards the body (Haggerty and Ericson, 605). This idea affirms that surveillance scholars have developed a partial democratization of 
surveillance hierarchy. Overall, the authors' approach tends to place importance on social and cultural effects of technological capabilities, particularly of the functioning of a dialectic embedded in surveillance practices.

Examining the forces and desires that give rise to and sustain the surveillant assemblage, the authors note the levelling of hierarchies into a rhizomatic expansion. Rhizomes, a term borrowed from Gilles Deleuze and Felix Guattari (1987), are plants which grow in surface extensions through interconnected roots oriented in a vertical fashion (Haggerty and Ericson 2000, 608). As a metaphor, the rhizome connotes surveillant technologies without a central structure, operated by variation and horizontally fragmented expansions. Haggerty and Ericson argue that the late modern period has allowed for the propagation of information gathering techniques that tend to break the human body "into a number of discrete signifying data flows that are further reassembled as functional hybrids whose convergence is found in temporal moments of interdependence" (Haggerty and Ericson 2000, 609). The resulting surveillance simulations bring together an inexhaustible range of information to formulate categorical images or risk data profiles which render obscure flows of information as comprehensible. Kirstie Ball (2006) criticizes Haggerty and Ericson for overlooking the possibility of resistance to surveillance; she states that the target of the generic surveillant assemblage is the human body and that it is not the identity or subjectivity of the individual that is important, but the data that is yielded from it (Ball, 301).

In a more recent analysis theorizing surveillance, Haggerty (2006) notes that the previous and much sought after problems of surveillance have become obsolete due to the enjoyable characteristics of surveillance. Referring to Web logs and Reality TV, 
Haggerty points to the appeal of leisurely scrutiny when people watch others subject themselves to public inspection as itself a pleasurable activity, concluding that surveillance can be experienced as a form of empowerment, fun and liberating, which clearly does not fit into the traditional understanding of the panoptic model (Haggerty, 28). Further it speaks powerfully to my own analysis.

Although Haggerty criticizes the panoptic approach, he does look into Foucault's later work on governmentality to demonstrate the need for a new model. Haggerty contrasts the distancing of agency between the panoptic model, and surveillance technology today, noting that the watch guard no longer exists. Contemporary technological devices do not require human agents to be present for them to function. Technology has reduced the ratio of human to technological monitoring and the human role is to monitor the technology that scrutinizes the behaviour of other people (Haggerty 2006, 32). Haggerty thus problematizes Foucault's failure to place importance on who is doing the watching and claims that the bias of the observer is vital in shaping the form of the response (Haggerty 2006, 33).

Surveillance technologies like CCTV, RFID chips and biometrics all involve a relationship between the physical body and the digitized body. Raising ethical dilemmas, Lynsey Dubbeld (2003) argues that body representation techniques, such as CCTV, produce constructions of the subject that involve judgment and discriminatory processes of categorization, and are therefore based on asymmetrical power relations between observers and observed (Dubbeld, 151). Dubbeld claims that the visualization processes enabled by CCTV result in the disappearance of the human physical body; it only remains significant in that the digital abstraction of the physical body can have palpable 
consequences for the embodied self and its life chances (Dubbeld, 152). Dubbeld further states that CCTV cameras and other forms of visual surveillance tend to transform the physical features of the body into digital codes, reducing it to a virtual, symbolic form (Dubbeld, 153).

Dubbeld's critique of the digitization of the body stems from her analysis of the observed and the observer. She highlights the asymmetry in terms of their respective embodiment, in that the camera operators are hidden from view and are thus, beyond scrutiny, while the observed body is exposed. The observed thus play a major role in a disembodied sense; they are not confronted directly and visibly, but rather through the mediating gaze that produces digital representations of the body (Dubbeld 2003, 155). Echoing the criticism of the panoptic, Lauren Goodland's (2003) historical genealogical analysis of Victorian Britain and her critique of Foucault's panoptic model, confirms Dubbeld's notions, in that it focuses on how the Foucauldian understanding of the panoptic misreads Bentham's principle of construction in favour of a model of society as a whole. Thus her analysis points at how the asymmetry of power raised around the exercise of surveillance is overlooked, and that we fail to consider its moral dilemmas.

Dubbeld, much like Irma Van der Ploeg (2003), argues that once digitized the physical body appears to be of no value. The source of information that is deemed valuable comprises the digital data abstracted from the body, and the embodied actor, him/herself, is in no way directly confronted (Dubbeld 2003, 160). Van der Ploeg takes this notion further by applying it to biometric technology. She notes that the justification of the use of these technologies, tends to misguide people regarding its invasiveness. They therefore tend to overlook the ethical issues regarding such surveillance. In other 
surveillance. In other words, by not assuming the invasive nature of its process, the debates surrounding the technology become oriented toward the invasion of the private sphere, rendering the body irrelevant (Van der Ploeg 2003, 88).

Ball (2006) refers to Van der Ploeg's work on biodata as a different category of information, which focuses on the body rather than the person, and thus gives rise to new ontology of the body as information (Ball, 308). She notes that the Human Genome Project, DNA, and hand geometry all enable a reading of the body by its codification in information. She explains that during the act of extracting information from the body there are rules applied to how the body and the integrity of its boundaries are treated in test scenarios (Ball, 308). Van der Ploeg's idea resides in the notion that if an informationalized body ontology is emerging, the point at which the body itself ends and the body as information starts, will begin to shift. Van der Ploeg's example, to which Ball refers, is that of the iris scan that is employed as a security device for entering buildings. Van der Ploeg notes that "iris scans are a more severe breach of bodily integrity than searching lower body openings for drugs", due to what information the iris scan reveals about the identity of the person (Ball, 308).

Ball states that it is important to understand the nature, multiplicity and simultaneity of contact points between bodies and surveillance technologies (Ball, 309). The point of contact is not on the surface of the body; rather they are heterogeneously located and distributed throughout the rhizomatic networks which constitute the surveillance assemblage (Ball, 309). The extent to which the body can be pinpointed as a source of truth, is a starting point for challenging biotechnologies that specifically locate the body as a site of ultimate truth or authenticity about the person (Ball, 309). Haggetty 
and Ericson point to this, in their own understanding of surveillant assemblage, claiming that the body is not the source of truth; however, they do not venture into understanding the inbetween-ness that leads to cyborgian theory.

In a recent article, Lyon (2006) further looks into the theoretical problems that concern the body and technologies which include the tension between watching and being watched. He works within the self-disciplinary nature of the Foucauldian perspective, yet he questions its application, noting that if it is applied in a subtle manner, it will lead to desired docile bodies. If rigorous, however, it will lead only to active resistance (Lyon, 3). He thus points to consumption and entertainment as the most powerful modes of surveillance. Referring to Reality TV, Lyon notes that these genres have helped make surveillance seem beneficial by equating pervasive monitoring with creativity and self-expression (Lyon, 14). Quoting Gandy, he emphasizes the idea that TV watchers are more inclined to think that businesses can better meet individual needs and that they believe that if one is bothered about the privacy infringing nature of surveillance, they have something to hide (Lyon, 14).

Maria Los (2006), also attempts to understand people's acceptance of surveillance, and she suggests that it is their ignorance of its consequences. An interesting approach to surveillance and people's attitudes that Los brings is her comparison of contemporary surveillance societies with totalitarian regimes. She states that in a totalitarian regime, society is atomized and the trust between people is broken, while today, the same is accomplished through moral panics and the war on terrorism (Los, 82). People have come to question others, believing that there are motives to lie, thus depending on surveillance technology to supplement for the lack of truth. Although she 
does not use the language, I would suggest she is invoking surveillance technology as witness.

Referring back to Foucault's work, in his research on the history of western social control, Foucault described the torture of a criminal as a 'carnival of atrocity', which demonstrates the display of power and knowledge, inscribed on the body (Staples 1997, 94). William Staples applies this notion to today's modern disciplinary technologies in his assertion that they are founded on the desire to derive knowledge from the body (Staples 1997, 94). The new disciplinary techniques reduce the need to trust the word of offenders, or for suspects to speak the truth, but rather rely on their objectified bodies to provide us with essential information (Staples 1997, 95).The body itself becomes a source of information through the use of technology, thus, technology helps to mobilize surveillance. Like Staples, I hope to draw similar findings through a focus on the change in the language of surveillance in the media. I will concentrate my analysis primarily on the nature of the witness and the impact of this subject position on the normalization of surveillance technology. Further, drawing on Law \& Order and CSI, I, too, focus on the realm of popular culture as a site where potential anxieties about information technology can be quelled.

As the above discussion demonstrates, technology mobilizes surveillance from its fixed structure in and of the panoptic to the mobile forms such as camera phones and databases, thus changing the way in which people use and perceive technology. Although the disciplinary notions that Foucault set forth have been a predominant basis for previous scholars' research on the topic, the advancement of surveillance devices and the integration of surveillance into everyday society has required us to change our approach 
towards surveillance from a dystopic big brother vision to a discourse which emphasizes its promised potential and the convenience it provides. Although academic writing has noted these changes and has re-conceptualized Foucault's theories, it has done so primarily through the framework of risk and discipline. I suggest there exist reasons beyond fear and risk that globalize and explain this phenomenon and look to popular culture for answers drawing upon scholars such as Haggerty (2004), Lyon (2006), Marx (1996), and Mathieson (1997). One key site where this plays out, I suggest, is in the representation of the witness, a figure who, by its very definition, surveils.

\section{Defining the Nature of the Witness}

In reference to Hanson's poetic articulation of the relationship between the polygraph with the live subject, the notion of the witness stands out as a concept of particular interest. Questioning a subject's confession, the polygraph is employed to ascertain the facts, and to confirm or reject the live subject's word. This spells out both the distrust of the live subject and the credibility afforded to a technological device. The polygraph's reading then becomes the accepted version of events to those interested. The polygraph replaces the subject as witness to the facts. Overall, one can see how through this relationship with the subject, the polygraph takes on the role of a witness, disclosing the pertinent information. This re-conceptualization of the witness is what I want to take to my objects of analysis, in order to explore what exactly the role of the witness contributes to the discussion of surveillance through a focus on truth, embodiment, agenlcy and morality as factors in its definition. 
The witness in its most simplified sense is summarized as an act; "To witness is to speak or write of what one saw with one's own eyes or heard with one's own ears of an experience of which the speaker/the writer has a firsthand knowledge" (Iyer 2003, 38) As a sensory experience, the witness is one who speaks for someone or something other than him/herself, who cannot speak or be heard; the witness thus makes a claim for the absent and the bygone (Pinchevski 2001, 80). The responsibilities of being a witness involve the moral compulsion to speak for Others without any guidance as to how one should do so; it is a demanding and unlimited responsibility that evokes anxiety of what one should do with a particular experience. As Donna Haraway (1997) defines it, the witness does not add from his or her own opinion, but is endowed with the power to establish facts. Witnesses are objective and guarantee the clarity and purity of objects. Their subjectivity is their objectivity (Haraway, 23).

Communication is key to witnessing. If one fails to communicate, one fails as witness. Witnessing is also about being heard. As Primo Levi, a holocaust survivor, clearly states, his nightmares while in the concentration camp were not about the events that unfolded daily, but about the freedom and the responsibility to report, as well as the failure to do so, when people are not listening. An experience, whether good or bad, only elicits meaning when its subject adopts the role of a witness and is heard by others. Witnessing is thus a social obligation to the Other. The experience is not what makes one a witness, but rather, answering and the responsibility taken to talk about that experience (Pinchevski 2001, 81-82).

The vocabulary around the witness places it within the realm of a truth claim. To mobilize witnessing, one must first see and experience and then relay back the 
experience. The act of witnessing exists in a relationship with testifying, which constitutes a recognizable, institutionalized process. This element of truth becomes a necessary part of using surveillance technology as witness, since surveillance devices are perceived to be neutral, and thus detached from the inaccuracies of human behaviour. As the witness represents the Other, the witness's own character and status becomes an issue, altering the power inherent in their testimony. Surveillance technology, in contrast, does not undergo the same degree of suspicion and scrutiny; it represents the Other, the corpse, the one who can longer witness or the absent spectator, the one who did not see or cannot testify.

In John Durham Peters' (2001) definition of a witness, the term connotes more than its grammatical meaning as a noun or a verb, but includes the depth of its historical context. In his work, Peters touches on the role of the witness as well as the role of the audience. Peters' analysis is particularly useful in that he links the role of the witness to surveillance. Taking into consideration the capability of surveillance technology, such as a camera shot, he argues that such devices substitute for the eyes or ears of those audience members who cannot witness for themselves (Peters, 707). The notion of witnessing raises questions of truth and experience, of perception and presence, and is fundamental to communication studies due to its ability to transform from experience to discourse (Peters, 711).

Noting that memory is rife with inconsistency, and that certain motives induce people to lie, Peters states that a camera, or a tape recorder, can conversely present images and sounds as they happen, "without the embellishments and blind-spots that human perception and memory routinely impose" (Peters 2001, 708). He further 
recognizes that witnessing is a sensorial act. Quoting John Ellis (2000), Peters states that television, in particular, has expanded the realm of sensory evidence, which is separated in space but united in time: "the co-presence of the television image is developing a distinct form of witness" (Peters 2001, 708).

When applied, much of the literature on the witness and the act of witnessing tends to be technical, focusing primarily on the role of the witness in legal proceedings. Peters, however, categorizes the witness as "the act, an act, the semiotic residue of that act and the inward experience that authorizes the statement" (Peters 2001, 709). Witnesses serve as the "surrogate sense-organs of the absent" and this obliges them to tell the truth. Peters also points out that fabrication in witness statements is inherent, as witnesses are a fallible transmission and storage medium for sensory experience (Peters 2001,710 ). He claims that witnesses, human or mechanical, are contradictory and inarticulate. Eyewitness testimonies have been subjected to intense social-psychological scrutiny (Peters 2001, 710). Peters quotes Aristotle, who claims that dead witnesses are more trustworthy since they cannot be bribed (Peters 2001, 711). This point is further emphasized by shows like CSI that purport that 'the evidence does not lie' and that a dead body is a more trustworthy witness than a live subject. The dead body is the haven of truth.

This understanding of the witness that Peters provides and the CSI franchise exhibits, allows for a dialogue between the discourses which posit the legitimacy of surveillance technology as a witness versus those preferring the human subject. This tension is highly visible in the programs I have selected for my analysis. I seek to examine the role of the human subject, as witness, relative to that of surveillance 
technology as witness. ${ }^{1}$ This further allows us to probe the flaws of both the human subject and technology, raising questions of the way in which surveillance is conveyed as an extension of the witness. Moreover, it allows us to tackle what is of importance in the relationship between the witness and technology. As Peters mentions, "the whole apparatus of trying to assure truthfulness, from torture to martyrdom to courtroom procedure, only testifies to the strange lack at its core" (Peters 2001, 713). The lack Peters refers to is the truth; he further states that witnessing is necessary in court cases but it no longer secures a conviction or acquittal.

My analysis of the literature raises the question of whether a witness necessarily entails a human, sensing body, or if it can be a surveillance device? The language surrounding the witness parallels the way in which surveillance technology is constructed in popular culture: it occludes our understanding of the relationships of the body to technology as distinct entity, and therefore changes the nature of the witness. As the medical examiner on CSI Miami states, "the body is always the best witness" (Tinder Box, 1-22). ${ }^{2}$ This thesis will be divided into three chapters. The first posits the CSI and Law \& Order franchises as overall narratives of surveillance. I then take up each franchise's representation of the witness, suggesting two different models of the ideal relationship between bodies and technologies: prosthesis and posthuman replacement. Through troubling these understandings of the relationship between the body and technology, we will gain significant insight into the nature of the witness and conflicts of truth and morality in contemporary surveillance society. Finally, we will be somewhat closer to understanding how surveillance technologies are normalized.

\footnotetext{
${ }^{1}$ The reference to the body is understood as the human subject unless it otherwise clearty states the body, or when talking about the body and its materiality.

${ }^{2}$ Originally aired 5/5/03.
} 
'Ripped from the Headlines', The Sub-culture-Driven Taste of the Crime Action Drama

One popular culture site where the relationship between technologies of surveillance and acts of witnessing are foregrounded is the crime action drama. In this genre, we see the complex relationship between bodies and technologies when we concentrate on who is a reliable witness. I will be focusing on two series which offer contrasting views of the witness.

The Law \& Order and CSI franchises are repeatedly found among the top ten viewed programs according to Nielsen ratings. In addition to having vibrant fan cultures, they have also both drawn academic attention in the fields of media studies and criminology. Such academic work has tended to focus on their voyeuristic gaze, their panoptic elements, and their portrayal of both crime and the criminal justice system.

This thesis will subject both franchises to an extensive ${ }^{3}$ analysis to explore the relationship between the body and technology, the nature of the witness, and the relationship between the witness and surveillance technology. Primarily focusing on how truth is constituted through the practise of witnessing and how morality is then played out, the notion of reliability will also be examined with regard to the kinds of machines used, the authority given to them, and the way in which they witness a crime. The concept of morality is central to this project, as it participates in the discourse of the body and technology, and of surveillance as a tool to witness and represent the Other.

Law \& Order presents a conventional style of crime solving that involves face-toface interviews with suspects and witnesses which invariably leads the detectives, at first,

\footnotetext{
${ }^{3}$ The 'extensive' analysis will be explained in more detail on page 24.
} 
on a number of dead ends, but through increasingly refined witness reports, questioning motives, and line-ups, they locate and arrest the alleged suspect. In the second half of the show, this suspect is either convicted or acquitted. The detective work does not end once the prosecution begins, but continues in the work of the district attorneys. The franchise represents the human motives to lie and how the criminal justice system works. Relying primarily on human subjects as witnesses, the plot does dabble with surveillance technologies such as security cameras, GPS locators, phone tapping, and transaction records, but these technologies of witnessing are used as an extension of the live witness's words, either for further evidence, or to unravel the flaws in surveillance technology's role as a witness. The plot raises discernable moral issues, often through its discourse of surveillance. It focuses on the search for truth achieved through 'traditional' means.

CSI tends to rely heavily on the technologized witness through forensic science and surveillance technologies. The live witness is secondary to the stylized edited scenes of testing gun-shot angles, DNA found at the scene, and the massive databases, surveillance cameras, and heat imagers employed. The show is highly invested in the use of technology as the narrative highlights its positive aspects and the legitimacy of surveillance as a tool to explain the particulars of a specific crime. The human subject is depicted as an untrustworthy figure with motive to lie, because they have either committed the crime, have something to hide, or simply due to the inherent inaccuracy of their testimony. When a witness provides their account of the crime, the investigators 
question the validity of the subject's word, returning to the evidence: "we'll look to Jill's body to confirm your story" (CSI Miami 'Tinder Box' 1-22).

Scholarly work surrounding Law \& Order concentrates in part on the way in which it both represents racial issues, and blurs the line between reality and fiction, not only through its practice of taking stories from actual news headlines, but also through its portrayal of criminal activity which further foster and sustain 'modern racism' (for eg. Eschholz et al. (2004) and a growing body of work including Price (1993) and Rapping (2003)). No scholarly work that I identified focused on issues of witnessing within the franchise despite the witness's central role within the storyline of each episode.

In contrast, the scholarly work on $C S I$ is heavily concentrated on what is referred to as the 'CSI effect'. The CSI effect describes the supposed influence of watching the show on jury behaviour. The claim is that jurors who see the high-quality forensic evidence presented on CSI develop standards for evidence which far exceed the actual evidence presented in real trials, which is typically more flawed and uncertain (eg. Tyler 2006). As a result, the assumption is that jurors affected tend to acquit defendants more frequently. This literature posits the show's tangible effects on the public's attitude towards surveillance technology, and the legitimacy they attach to surveillance for witnessing a crime, as opposed to the testimony of the live subjects (Tyler 2006, 1065). ${ }^{5}$

Other work dealing with CSI focuses on how it extends a panoptic gaze, enabling science to succeed where policing and the manipulations of lawyers fails. Sue Tait's (2006) work, although predominately dealing with CSI's necrophilic imagery, also focuses on the way in which surveillance devices are legitimated over the human subject.

\footnotetext{
${ }^{4}$ Originally aired $05 / 05 / 03$.

${ }^{5}$ Other literature on the 'CSI Effect' includes for example, Mann (2006) and Heinrick (2006).
} 
She claims that "if there's a strand of hair or a partial fingerprint, science and high-tech gadgetry can provide irrefutable answers" (Tait 2006, 53). Quoting Jeffrey Zaslow (2001), Tait states, in reference to the machinations of the modern justice system: “eyewitness and confessions don't work any more; in court lawyers turn it all around, criminalist's are the only guys who can prove you are guilty" (Tait 2006, 58). Tait further emphasizes the role of the CSI crew by noting that "crime is dealt with hygienically by teams of elite scientists who bring truth to light with superhuman haste" (Tait 2006, 59). Tait's argument is useful for my analysis, as it allows me to raise questions regarding the role of the witness, who/what is identified as a witness, how technology is used as an information source, and the role of forensics as evidence.

Applying Tait's argument to Law \& Order, the show differs in that it refutes the notion that surveillance technology can prove guilt. In an episode of Law \& Order: Special Victims Unit, a man accused of murdering his wife based on evidence of a credit card transaction showing the purchase of poison, is told by the district attorney that the paper trail he has left behind holds more strength than the testimony of three witnesses claiming the impossibility of his involvement ('Choreographed' 8-17). ${ }^{6}$ However, as the program tends to refuse the power of the technology over the subject, it ends with recognition that the accused was framed. The show employs such plot twists to affirm the legitimacy and power of the live subject, re-emphasizing the historical and academic understanding of the nature of the witness.

Dealing with CSTs use of crime-as-spectacle, Martha Gever (2005) states that according to the show: machines do all the work, the fingerprint matching process is represented as definitive, and DNA analysis is presented as foolproof evidence of guilt

\footnotetext{
${ }^{6}$ Originally aired $11 / 28 / 06$.
} 
(Gever, 453). In other words, the author concludes that "if CSI crime laboratory workers declare a match between two DNA samples, whoever is the source of the genetic material might as well forget about hiring a lawyer" (Gever, 453). The article further states that in CSI, the search for truth has been relocated in concert with a more general cultural turn, from reading minds to reading bodies (Gever, 455 ). The laboratory science tends to be depicted as superseding self-revelation and eliminating the problem of human fallibility, deceit, inaccuracy or ignorance (Gever, 455). Gever's analysis can be used to differentiate $C S I$ from Law \& Order: the human fallibility that CSI emphasizes is also conveyed in Law \& Order; but the latter generally ends with the confession of a live subject, whereas the former relies on the findings of surveillance technology and legitimizes forensics over confessions.

Gever also states that the attention-grabbing digital video images that are employed engage viewers in mysteries best solved using high-tech forensic investigative techniques and that $C S I$ is unique among crime dramas in the way in which it provides occasion for audiences to engage with displays of power presented as technological mastery (Gever, 447-448). Specifically, Gever notes that the voice-over, used to recall the events of the crime to the audience, which is illustrated by stylized manipulated images, tends to underscore the concept of crime-solving as visual. However, since these montages are most often found ultimately erroneous, the scenes imply that truth is detected best by machines, rather than mere humans (Gever, 460). This characterization is typical of the way in which the program questions the legitimacy of the human witness. In the field of criminology, there is a likewise emphasis on crime drama programs and as Aaron Doyle (1998) demonstrates, it is significant that media products are not 
consumed in isolation. Doyle proposes an argument that can help explain the effect of Law \& Order and CSI on the audience's perception of both the role of the witness, and the use of invasive surveillance techniques, which tend to shift our social and cultural attitude and beliefs. Doyle presents three forms of influence which include i) media products influence each others meaning and that people do not consume in isolation, ii) mass media shape the practices of other institutions, iii) media are implicated in opinion formation of social and cultural shifts (Doyle, 95). Doyle's arguments work well in assessing both how the role of the witness has changed and how we come to understand the legal system.

Doyle also mentions that the 'Law and Order ideology' appeals to audiences looking for a focus for their anger (Doyle, 97), and that while visual evidence tends to play more of a supporting role in news, drama shows like Cops and Law \& Order, support the pervasive cultural understanding that 'seeing is believing' (Doyle, 99). This notion is further strengthened by virtue of the fact that surveillance recordings tend to provide a stronger witness in a crime case, since the act of 'seeing' via technology is stronger than eyewitness accounts of an event. This thesis will engage with the dialogue which questions the shift in the nature of the witness. Is surveillance technology, in its most invasive form, an extension of the human witness, and thus a modern necessity? If so, does this explain the normalization of surveillance technology?

My analysis includes a selection of episodes from both the Law \& Order and CSI franchises to study the relationship between surveillance technologies and the body, and the impact of this relationship on the witness. The selection involves episodes from each show post 9/11, two years after the attacks and following the passing of the USA Patriot 
$A c t^{7}$, in order to explore the increase in use of surveillance technology as a means to combat uncertainty, at a time when both shows and their franchises were at their peak. This includes episodes aired in $2003-2004^{8}$, broken down as season 14 of Law \& Order, season 5 of Law \& Order SVU, and season 3 of Law \& Order CI. ${ }^{9}$ For CSI, season 4 of CSI, season 2 of CSI Miami and season 1 of CSI NY. Each season consists of approximately 20 episodes and my analysis has involved viewing specifically the beginning of the season, one episode each month, from September to May, and the season finale.

The findings are based on the information collected and organized in response to a question sheet created prior to viewing the programs. During the collecting and analysing of the programs, the episodes were coded by investigating common elements concerning the discourse of surveillance: how evidence was constructed, who or what was a witness, as well how the truth was achieved, what was given legitimacy, and the episode's moral message. The relationship between the witness and the body, technology and the body, and that of surveillance and the live subject were at the core of each question asked. As well, I examined the way in which the construction of truth and the moral issues raised within the episodes alter the perception towards surveillance either positively or negatively.

The analyzing of the episodes was completed in two steps. The first step was a question sheet consisting of a list of questions that were asked while watching each of the

\footnotetext{
${ }^{7}$ The full legal term is 'Uniting and Strengthening America by Providing Appropriate Tools Required to Intercept and Obstruct Terrorism Act' of 2001. It was signed into law by President George W. Bush on October $26^{\text {th }} 2001$.

${ }^{8}$ CSI NY includes episodes from 2005 as well due to its later aired date.

${ }^{9}$ All three of the Law \& Order series were studied but as Chapter 2 will explain, Criminal Intent was not used in the dialogue presented in Chapter 3.
} 
episodes listed. Once completed, the information consistently demonstrated two distinct themes, that of prosthesis and replacement, and thus the two categories as frameworks were taken into consideration and the programs were revisited with a second set of questions. The findings in the second round, demonstrated a clear categorization that separated the programs and even the franchises, and distinguished the framework that was to be employed when analyzing the two franchises, on their own in relation to body and technology, and together in dialogue with one another. As well, much of the concepts that are addressed within each chapter and in the conclusion, are in response to the collective information that was generated through the question sheets. ${ }^{10}$

The thesis is organized into five chapters, including the Introduction. Chapter Two will provide a more detailed description of the two franchises, including the characters, the actors that play them and the character development within each of the six series. The second part of that chapter will be an analysis of themes present in both franchises that frame them as surveillance narratives.

In Chapter Three, I turn to Law \& Order suggesting the relationship between surveillance technology and the witness is one of prosthetics. As an extension of the body, Marshall McLuhan and other scholars' notions of prosthesis will help set up the dialogue within this chapter. The relationship between surveillance technology and the body will help explain how surveillance is seen as a positive addition to the act of witnessing but also to the body, thus helping to reclaim the role of the human subject.

The fourth chapter takes up the CSI franchise and examines the idea of replacement, as technology is granted legitimacy over the human subject. Employing a posthumanist literature to frame the discussion, the relationship between the body and

\footnotetext{
${ }^{10}$ A sample of the question sheet can be found in the appendix of this paper.
} 
technology will be targeted to analyse the dichotomy between the witness versus the evidence, and that of subjectivity versus objectivity. This franchise conveys surveillance technologies as replacing the live subject in the act of witnessing and I provide various examples. This will help raise questions of both the relationship between technology and body, between surveillance and witness and how we may come to perceive surveillance as non-threatening, even when it is replacing us. The final chapter compares and contrasts the discourses of the witness in the two franchises and links this discussion back to the overall problems of surveillance. 


\section{Chapter 2}

\section{Law \& Order and CSI as Surveillance Narratives}

The Law \& Order and CSI franchises have managed to become not just another set of television programs, but have infiltrated much of television's program grid with over fourteen hours of the CSI franchise and five episodes of the three Law \& Order series playing each day (not including the new episodes of each series on prime-time each week). ${ }^{1}$ The Law \& Order franchise includes DVD box-sets for seasons one to three and five of Special Victims Unit, seasons one to three of Criminal Intent, and five seasons on DVD of the original Law \& Order. This is accompanied by a detective board game, six video games and 13,000 fan sites. The CSI franchise involves a total of eight episodes per day of CSI Miami, along with three episodes of CSI: NY and three episodes of CSI. There is a CSI: Miami soundtrack, over five video games, two board games and a total of 52,000 fan sites, including fan sites for each particular character and star.

Collectively, the two franchises have generated eleven video games, adaptable on Windows 98, Playstation 2 and Mac OS X, along with online trivia questions, board games, live chat rooms, official websites, and numerous Emmy Award nominations. The ubiquity of the six series in popular culture, including Law \& Order's seventeen year run, makes both franchises, in and of themselves, very noteworthy cultural texts. Aired in over twenty-seven countries worldwide, and watched by millions weekly, their success and conscious dialogue with true to life events work to reflect society back to us and provide an interesting barometer of how we talk about what is going on in our society. I will explore both franchises in more detail below, with a view to demonstrating first, their social significance, and second, their construction as narratives of surveillance.

\footnotetext{
${ }^{1}$ This includes basic cable, up to channel 42, in the Ottawa area in summer 2007.
} 
The Law \& Order Franchise

The Law \& Order franchise was created by Dick Wolf and includes, Law \& Order, Law \& Order: Special Victims Unit and Law \& Order: Criminal Intent. Broadcast on NBC, the original series has been on air since September of 1990, while $S V U$ premiered ten years later in September 2000, and Criminal Intent, a year after that, in September 2001 (NBC: Law \& Order). All three series are targeted to the 18-49 yearold demographic. The three series differ in the cases they handle, the structures of the programs, and their character development. An Emmy award winning series, Law \& Order is a two-tiered program which divides the investigative segment, mobilized by police detectives, from the trial, where the District Attorneys attempt to bring 'order'. Achieving high ratings for the first 15 years, the show lost 1.8 million viewers in its $16^{\text {th }}$ season due to a change in its time slot, now on Fridays at 10pm. Averaging 9.3 million viewers each week, the show's ratings vary week by week, still occasionally making the Nielson top 10. Law \& Order is exported worldwide, airing in twenty-seven countries.

The cast of Law \& Order has changed throughout its seventeen year run and in its current season the senior detective is Ed Green (Jesse L. Martin). His partner is detective Nina Cassady (Milena Govich). Detective Green's style involves breaking the rules in order to get at the truth and to arrest suspects. In the particular season that this thesis focuses on, the lead detective was Lennie Briscoe (Jerry Orbach) with Ed Green as his partner (NBC: Law \& Order).

Briscoe entered the series in 1992. In his first four seasons he battled alcoholism, however he stopped drinking when a district attorney at the time was hit by a drunk driver. Briscoe's work has been affected by his drinking issues, but also by the murder of 
his drug addicted daughter after she testified in court against her dealer. ${ }^{2}$ The lieutenant, Anitan van Buren (S. Epatha Merkerson), is responsible for her detectives and for ensuring that the interrogations go well, in other words, that everything is 'by the book'.

The main staple of the series is District Attorney Jack McCoy (Sam Waterston). $\mathrm{He}$ is ruthless and aggressive when it comes to getting guilty verdicts. $\mathrm{He}$ is passionate about his work and his motivation is a desire for justice. His personal life is rarely developed other than the incidental criticism he receives for being a womanizer and having affairs with four of his past assistants (NBC: Law \& Order). His assistant in season fourteen, Serena Southerlyn (Elisabeth Rohm), is at times at odds with both McCoy and D.A., Arthur Branch's (Fred Dalton Thompson) decisions. Southerlyn was later fired in season sixteen when she showed undue sympathy to a defendant.

Law \& Order: $S V U$ is currently in its $8^{\text {th }}$ season. It is the highest-rated series of the Law \& Order franchise, averaging 12.9 million viewers each week in 2007 , and is one of the highest rated shows on NBC. Solving cases that deal with sexual assault and rape, $S V U$ is aired in twenty-seven different countries. $S V U$ follows the same two-tiered style as the original, but has become more character driven than the other two series. This development occurred in the 2005 season where the spotlight slowly drifted from the crimes to the relationship between its two main detectives, Olivia Benson (Mariska Hargitay) and Elliot Stabler (Christopher Meloni).

Stabler is a dedicated detective who lets his rage get the best of him, which puts strain on both his family and partner. Over the past two years, Stabler's personal life has become a sub-plot in itself, from how he disciplines his children, to his obsession with

\footnotetext{
${ }^{2}$ Briscoe retired from being a detective at the end of season 14 and became a DA investigator in the spinoff Law \& Order: Trial by Jury before the actor's death in 2004.
} 
work, resulting to his separation from his wife. He has admitted to the questionable desire of wanting to kill the offenders he faces, which has, at times, almost cost him his job.

Stabler's partner Benson is guilt-driven. She tends to get too close to her victims and has therefore been accused of being biased. Her job too takes precedence over her personal life, resulting in an underdeveloped social life outside of her police work. Benson is a child of rape, her motivation for joining the SVU, which becomes an issue when she deals with rape victims, who as a result of their victimization, become pregnant and must make decisions regarding abortion. Stabler and Benson have formed a special platonic bond that is evident in the way in which they 'cover' for each other in their case work.

The other detectives in the series include Detective Munch (Richard Belzer), a conspiracy theorist, and Detective Fin Tutuola (Ice-T), who can relate to suspects from poor areas because of his similar background. Captain Donald Cragen (Dann Florek) is responsible for the detectives, while Dr. Huang (B.D Wong), a psychiatrist, attempts to understand the offender's mental state. Finally, the Assistant D.A. Casey Novak (Diane Neal) takes over in the second half of the show, bringing the offenders to trial and answering to Bureau Chief, Elizabeth Donnelly (Judith Light).

The third series in the franchise, Law \& Order: CI, is currently in its sixth season. Criminal Intent follows the Major Case Squad, which tackles high profile homicides of VIPs, local government officials, the art world, as well as some smaller homicide cases in a manner similar to the original series. This series differs from the other two in that it focuses on the actions and motives of suspects rather than on the police and prosecution 
sides of the cases. As well, while the other two series open with a non-recurring character(s) finding the body, Criminal Intent begins with a teaser introduction of cutscenes that reveal the future suspect(s) or victim before the act, thus providing a psychological puzzle for the audience to piece together as the case unfolds. Criminal Intent demonstrates investigative work motivated by psychological analysis and profiling rather than material evidence and witness testimony. Averaging 9.7 million viewers each week, its international viewing audience includes fifteen countries.

Divided in 2006 into two teams, the original team consists of Robert Goren (Vincent D’Onofrio), whose intuition, broad knowledge and investigative style invariably helps break the cases and his partner, detective Alehandra Eames (Kathryn Erbe), who is known for her dry sense of humour and sarcasm. Goren is portrayed as a highly functioning autistic who can focus on details and makes connections which others overlook. Eames is practical and adds a nice balance to her partner's intense methods. The second team consists of Detective Mike Logan (Chris Noth), returning after a long hiatus from the original series, and his partner Detective Megan Wheeler (Julianne Nicholson). The A.D.A. is Ron Carver (Courtney B. Vance), who is at times at odd with the detectives because they work on hunches, rather than evidence, to seal the case. In season three, the Captain was James Deakins (Jamey Sheridan), a strong supporter of his detectives; he had to retire early because this support got him into trouble. In the current season, Captain Danny Ross (Eric Bogosian) is his replacement.

There is a key structural difference between Law \& Order: CI and the other two series in that in the former, the detectives' work fills the entire episode. Although the District Attorney is involved, s/he appears only in the last scene leading to the arrest of 
the criminals and their plea bargain. Criminal Intent does not put the cases through trial. Furthermore, although all three series depict detectives playing 'good' cop and 'bad' cop in the interrogation room, Criminal Intent uses tricks and twists to pin one suspect against another to get at the truth.

For my analysis, I will not focus on Law \& Order: CI due to its extensive use of psychological analysis in solving the cases. Although surveillance technology and forensics are present as an extension of the investigator's work, they are minimally used and rarely emphasized; rather the focus is on the weaknesses of human intent and behaviour. The suspect, rather than the witness, lies at the heart of the plot. Criminal Intent does not function, as do the others, as a narrative of surveillance.

All three Law \& Order series, although the types of cases each handles are different, follow a 'ripped from the headlines' format, inter-textually linking non-fictional crime cases with fictional ones, and featuring a range of issues from sexual assault or murder cases, to world issues, to celebrity mishaps. Intertextual borrowings have included the Karla Homolka and Paul Bernardo case, the Treva Throneberry story ${ }^{3}$, the moral dilemmas of the Terry Schiavo case, and the Columbine High School shootings. The programs also cover top entertainment news. Photos of a celebrity being careless with her son, and of her marriage to a notorious womanizer, for example, allude to Britney Spears. A plot line which includes a drunken celebrity arrested for driving under the influence, and spewing derogatory remarks, offers a thinly veiled reference to the

\footnotetext{
${ }^{3}$ The Treva Throneberry story involves the case of the 31 year old who pretended to be 18 year old Brianna Stewart. As she moved from one foster home to another, the lack of paperwork made it impossible to prove her identity and hence she defrauded the government in foster care and educational fees. Finally arrested in Vancouver, Throneberry was psychologically distraught enough to have supposedly forgotten her own identity and become the 18 year old she played (White 2002:A2).
} 
most recent Mel Gibson arrest. These allusions add to the pleasure in viewing and produce an aura of verisimilitude.

\section{The CSI Franchise}

The CSI franchise also consists of three series, all created by Anthony E. Zuiker and airing on CBS. The original CSI debuted in October of 2000 and climbed from $10^{\text {th }}$ place on the Nielson scale to second place by the second season, further climbing to number one in its $3^{\text {rd }}$ and $4^{\text {th }}$ seasons. The series averages 25.27 to 26.20 million viewers each week. According to the 2007 ratings, after seven years, CSI is still holding strong at \#4 and bringing in over 20.5 million viewers weekly. Aimed at the $18-49$ year old demographic, the show can currently be seen in over seventy-three countries. The original CSI takes place in Las Vegas and features a team of forensic scientists. The division solves crimes almost entirely through means of forensic evidence and surveillance technology. Most of the episodes cover the resolution of two usually unrelated cases that are most often cracked without seeing the prosecution side of the case.

The original series consists of eight main characters which include the head of the team, Gil Grissom (William Peterson), who is an expert on insects and has an extensive scientific knowledge that contributes to the didactic tone of the series. Grissom is accompanied by Catherine Willows (Marg Helgenberger), who is a single mother and the daughter of a known dangerous casino mogul, Sam Braun. Willows' past includes waiting on tables before becoming an exotic dancer to help finance her education. Her specialty is blood splatter analysis. 
The rest of the team includes Warrick Brown (Gary Dourdan), an audio/visual analyst, Nick Stokes (George Eads), a hair and fiber analyst, and Sara Sidle (Jorja Fox), who specializes in materials and elements. Greg Sanders (Eric Szmanda) started off as a DNA scientist in the lab, but has since become a field investigator with an acute skill for detail that puts him on top of his game. Important other characters include police officer, Captain Jim Brass (Paul Guilfoyle), and Doctor Albert Robbins (Robert David Hall), who is the medical examiner studying the bodies post mortem.

CSI: Miami premiered in September of 2002 and has since become not only the number one show on Mondays in the U.S in 2007, but according to Reuters in 2006, the show is the most-watched U.S. series around the world (Bernhard, 2007). The ratings for the show in the U.S. have remained consistent ranging from \#14 in its first season, to \#9 in 2005 with 18.13 million viewers. CSI: Miami features Horatio Cane (David Caruso), the main detective and head of the lab, along with Calleigh Duquesne (Emily Proctor), a ballistics specialist, Eric Delko (Adam Rodriguez), an expert in fingerprint and drug identification, Ryan Wolfe (Jonathan Togo), a former police officer, and Natalia Boa Vista (Eva La Rue), a DNA analyst. The police captain is detective Frank Tripp (Rex Linn) and the medical examiner in this series is Alexx Woods (Khandi Alexander), who has an odd tendency of talking to dead bodies as she examines them. In the current season of the show, Ryan Wolfe is asked to leave the team as his gambling habits become an issue in a murder case that they are investigating. He is now a news reporter getting in the team's way while reporting on the details of the crimes.

The latest CSI series, CSI: New York, first airing in 2004, followed in the footsteps of the other two series. Bloodier than its two predecessors, its first two seasons 
were filmed in blue light which was later changed as it was felt this produced too cold an aesthetic (Tait 2006, 46). Although the show follows the same formula as the original, it has yet to be ranked in the top 10, even with an optimal time slot and carefully selected, famous cast. Coming in at \#21 and \#22 in its first two seasons, the show does however bring in 13.4 to 14.0 million viewers each week as of 2007.

CSI: $N Y$ involves Detective Mac Taylor (Gary Sinise), who is trying to bring order to his life after the death of his wife on $9 / 11$. His partner is detective Stella Bonasera (Melina Kanakaredes), whose childhood as an orphan and firsthand experience with the failures of the child welfare system affect her work and her approach to victims (CBS: New York). In season one, upon which I focus, investigator Aiden Burn (Vanessa Ferlito) is referred to, but has since left the show, however police Detective Don Flack (Eddie Cahill), and forensic experts Danny Messer (Carmine Giovinazzo) and Lindsay Monroe (Anna Belknap) still remain and play an important role in collecting and testing evidence. The medical examiners include Sheldon Hawkes (Hill Harper) ${ }^{4}$, Dr. Sid Hammerback (Robert Joy), with the most recent addition to the cast being Dr. Peyton Driscoll (Claire Forlani), who has become romantically involved with Det. Taylor.

In terms of plot formulas, similarities appear across the three CSI series: a team of investigators solves crimes. However while CSI and CSI: NY tend to focus on two coinciding cases that are at times linked, CSI: Miami highlights one distinct case. The CSI brand is subculture driven, dealing with current events that are complicated and conveyed through murder cases where the investigators often face the problem of having no eye-witness to these crimes. Their soundtracks, the technologies they employ, and

\footnotetext{
${ }^{4} \mathrm{He}$, too, has since become a field investigator.
} 
their conscious intertextual references to top-rated video games, the current reality TV craze, and other homages to youth culture, suggest that the series are very aware of today's popular culture and employ their cultural savvy to appeal to their target demographic.

For ease of comprehension throughout the thesis, I will be referring to the two of the three Law \& Order series and the three CSI series as 'franchises' when referencing all the shows within each group. The term 'franchise' will include only the three series of each show and not the merchandise, video games, board games, posters, soundtrack, etc., that make both programs a brand in their own right. I will refer to each distinct show (eg. CSI: $N Y$ or Law \& Order: SVU) as a series, and each individual program as an episode.

\section{Narratives of Surveillance Society}

The two franchises are crime dramas with a twist: they assume we live in a surveillance society, recognizing that we are all in the system and positing that technology is everywhere. Each can be productively read as a surveillance narrative. This narrative features the ubiquity of technology, the post $9 / 11$ world, a post-panoptic perspective on power, and issues of morality in the surveillant assemblage. In general, the franchises embrace surveillance technology when used by officials in positions of authority, while critiquing its more democratic potential and use.

For example, in Law \& Order: SVU, Det. Munch's conspiracy theories often focus on the dangers of technology, and the access to information by corporations, the state and others. In the episode 'Waste' (Law \& Order, 'Waste' 4-8)', when a comatose

\footnotetext{
${ }^{5}$ Originally aired $15 / 11 / 02$.
} 
woman is raped and left impregnated, the detectives try to collect DNA from those who worked at the hospital to find the offender. When suspect, Samuel Hill, refuses to give his DNA without a warrant, Munch agrees with his position:

Munch: "Hold on, Mr. Hill has a valid point. Our likes and dislikes, our habits are all stored in huge computer systems and on top of that you've got facial recognition technology, video surveillance ..."

Samuel Hill: "National ID cards, where does it end?"

Munch: "Every piece of data you put out there exponentially increases the amount of control The Man wields over you."

When Hill ends the conversation and leaves, Fin Tutuola fires back at Munch, "What the hell was that?" Munch quietly pulls out Hill's chopsticks from the trash, retorting, "Good police work: here's your DNA".

Munch continuously criticizes the advances in technology and the increasing accessibility of personal information. His contempt is not only conveyed in his dialogue with suspects, but also in his comments when the other detectives bring up surveillance technology in discussion. However, in the above situation, Munch's actions contradict his numerous references to Big Brother, in that he does not find it improper to use forensics for police work, resorting to gathering data without the subject's consent. As well, the risk of the critique he offers is further contained by his character's framing as an iconoclast.

The didactic dialogue between the detectives and the district attorneys in both of the Law \& Order series demonstrates their awareness that we live in a surveillance society, addressing its challenge when suspects use the technology to commit the crimes, 
as well as when the detectives make use of it for police investigation. Surveillance activities such as retrieving bank records or phone records are normalized, as is collecting forensic evidence in order to match fingerprints and DNA.

Bogard (2006) suggests that the State-couched surveillance language of 'safety', provided by the police and surveillance technologies of identification and verification, amounts to compiling access by the state to "everything about you and what distinguishes you from the other" (Bogard, 100). He notes that the normalizing of the gathering of data by authorities allows for the decoding and recoding of information, which only shifts the virtual forms of control, and transforms the individual into its data double (Bogard, 106).

Although the series recognize that technology is everywhere, they consistently address the problems posed by more invasive forms of technology. In Law \& Order: $S V U$ 's 'Choreographed' (8-9) ${ }^{6}$, the storyline adopts the Amal Graafstra and Jennifer Tomblin story in which both husband and wife inserted RFID chips under their skin. ${ }^{7}$ The episode twists the real life plot to present the story of a jealous husband who inserts the chip into his wife in order to track her whereabouts and, as a result, finds out that she is cheating on him. He then kills the other man's wife and frames him for the murder. When Stabler finds out about the RFID chips he is skeptical, to which the husband, Glenn Cheales, responds:

Cheales: 'RFID is the wave of the future; I'm just ahead of the curve. In fifteen years, everyone will be implanted with a chip."

Stabler: "Really? Where do I sign up to opt out of that?"

Cheales: "The backwards attitude of a typical Luddite."

\footnotetext{
${ }^{6}$ Originally aired 28/11/06.

${ }^{7}$ The case received a lot of press coverage. See for example, Mathieu (2006) and ('Couples' 2006).
} 
In the final scene, Stabler and Benson approach the advancement of technology and the possibilities it grants with disgust, offering a negative criticism of the modern surveillance system and ubiquity of technology. The critique is dulled however by the series' overall seeming embrace of other forms of surveillance technologies. Interestingly, the series' rejection of invasive technology suggests that such practices are not located on the same spectrum as the surveillance practices and technologies of the authorities, muting possible systemic avenues of critique.

In Law \& Order, the murder of a psychiatrist leads the detectives to a case involving a computer company that sells information. At issue is the company's responsibility in shielding its client's history in order to serve their needs. To personalize the risks of access to information, the dialogue demonstrates that everyone is a victim. Southerlyn confronts McCoy with the information that has been collected about him: McCoy is at the time reading Eleanor Roosevelt's Biography, and he listens to the Clash, the Beatles and fusion Jazz. Southerlyn, to McCoy's surprise, also indicates that she knows he is taking prescription medicine for migraines (Law \& Order, 'Access Nation' $12-15){ }^{8}$ This information demonstrates the alarming nature of ubiquitous information technology and confirms that everyone is a possible target. It seemingly rejects the notion that if you have nothing to hide, then you have nothing to worry about: the most intimate details of your life have now become an accessible public commodity.

In the CSI franchise, the presence of technology is much more visible and surveillance technology is treated very differently. The investigative camera shots of the scientists working in their labs, the information provided on the capabilities of the

\footnotetext{
${ }^{8}$ Originally aired $27 / 02 / 02$.
} 
devices employed, and the ease in tracking individuals, confirm that technology is everywhere. ${ }^{9}$ The franchise conveys a misconceived notion that very high end technology is widely available. In fact, the programs' gadgets and occasional use of yet-to be invented technology has arguably moved it at times into the science fiction genre. ${ }^{10}$ This has led to what I discuss in Chapter One as the 'CSI effect'.

Both the Law \& Order and the CSI franchises acknowledge that we live in a post9/11 world. In the former, not only do the detectives discuss the changes to the citizens of New York in the aftermath of the event, and highlight the changes in the laws, i.e. The Patriot Act, but numerous episodes revolve around the anger and racism that has increased after 9/11. In the original Law \& Order, the issue of targeting and questioning Muslim suspects is raised, as the show reveals the problems with racial profiling. In 'Melting Pot', when a filmmaker is killed after finishing a film that deals with the oppression of women under the Koran, the detectives suspect a Muslim sound-editor of the crime. After they interrogate him, they realize he is not guilty. Det. Nina Cassidy feels bad, but Van Buren states, wryly, 'I'm sure Mr. Mohammed is used to being a scapegoat by now' (Law \& Order, 'Melting Pot' 17-15). ${ }^{11}$

As well, both $L a w \&$ Order, and $L a w \&$ Order: $S V U$ bring an awareness of the effects of 9/11 to their main storylines. Ripped from the headlines, the two series have covered events such as the anthrax scare (Law \& Order: SVU, 'Counterfeit' 3-14) ${ }^{12}$, the

\footnotetext{
${ }^{9}$ An example includes the access to the DNA labs, as though all labs are as well equipped, and the ondemand efficiency of testing and getting results.

${ }^{10}$ One example of a yet to be invented technology is the access, the CSI team has, to a device that checks all U.S. airports passenger lists in real-time. (CSI: Miami 'Money for Nothing' 2-17). It was originally aired 3/1/2004.

${ }^{11}$ Originally aired 16/02/07.

${ }^{12}$ Originally aired 25/01/02.
} 
“Running Shoe Bomber” (Law \& Order, 'Access Nation' 12-15) ${ }^{13}$, and the John Walker Lindh case (Law \& Order, 'American Jihad' 13-1). ${ }^{14}$ As well, the often overlooked concept that Muslims were also victims of $9 / 11$ is recognized. In Law \& Order, the episode 'Fear America' deals with a Muslim man suspected of a murder. His lawyer states to McCoy, “On 9/11, my nephew died, he was a security guard in the South Tower. The following week, pig's blood was thrown on our mosque". McCoy responds, "We all lost that day". The lawyer counters: "Muslim-Americans keep losing" (Law \& Order, 'Fear America' 17-4). 15

In an episode of a shooting at 'City Hall', Law \& Order also critically addresses the government's use of 'secret warrants', the granting of FBI agents the right to search in, and confiscate from, the homes of those suspected in aiding and abetting terrorists. The secret warrants are a post-9/11 alteration to the law. The defendant's lawyer argues that if this fundamental breach of personal privacy is not revealed to the court of law, the state will possess unbridled power. Can they bug people's phones or hack into their computers? Or take their belongings on the grounds of suspicion alone? She hits the idea home by stating, "Next time, the home they enter in the dead of night can be yours" (Law \& Order, 'City Hall' 14-14) ${ }^{\mathbf{1 6}}$, suggesting that invasion of privacy can target anyone, not just the guilty.

In the CSI franchise there is also a clear reference to the post-9/11 world, particularly in CSI: $N Y$ as that series initially debuted after $9 / 11$ and specifically dealt with the event in its first season. Because the main investigator, Det. Taylor, lost his wife

\footnotetext{
${ }^{13}$ Originally aired 27/02/02.

${ }^{14}$ Originally aired $01 / 10 / 02$.

${ }^{15}$ Originally aired $13 / 10 / 06$.

${ }^{16}$ Originally aired $11 / 02 / 04$.
} 
to $9 / 11$, the events of the towers coming down that morning, and the continued impact of this tragedy are a constant element which affects the way in which he deals with problems and interpersonal relationships. Although less visible in the other two series of the franchise, the impact of $9 / 11$ upon access to information does become an issue, as does the fear of terrorism. In CSI: Miami's '10-7' $(3-24)^{17}$ the case involves the murder of a man hired to make dirty bombs, for a group of terrorists, to set off in Miami. The issue of a terrorist threat is also addressed in two back-to-back episodes in season five: 'Going Going Gone' (CSI: Miami, 5-9) ${ }^{18}$ and 'Backstabbers' (CSI Miami, 5-11). ${ }^{19}$ In the first episode, Horatio uncovers a deadly plot against the city of Miami and in the continuation, Sonya Barak, a suspected terrorist who orchestrated the initial attack, is standing trial. When the members of the terrorist group, with which she is associated, try to gun her down, Cane intervenes. The threats against Miami that these episodes deal with do refer to Al Qaeda, but the narratives become more complex and often end up focusing on home-grown terrorist acts, which have become an issue of increasing concern as of late.

Overall, CSI and CSI: Miami address our post-9/11 society more in terms of the introduction of new technologies and the subsequent changes in the laws. This may be due to the emphasis placed on technology, rather than on the moral impact 9/11 has had on America in its aftermath, as well as to the fact that the two series are not set in New York City. Even in CSI: NY, despite its proximity to the towers, the show deals with individual murder cases more often than terrorism, preferring to use 9/11's aftermath, and the risks of another attack, to further justify the need for surveillance technology.

\footnotetext{
${ }^{17}$ Originally aired 23/05/05.

${ }^{18}$ Originally aired 20/11/06.

${ }^{19}$ Originally aired $12 / 11 / 06$.
} 
Following $9 / 11$, the CSI franchise only specifically undertakes a discussion of the war in Iraq in some of the CSI: Miomi episodes. This issue is wholly absent from CSI: NY and the original CSI. In CSI: Miami, when a marine is found dead, the team's investigation of the situation takes them to the front-lines in Iraq, to uncover an American bullet manufacturer's wrongdoings (CSI: Miami, 'Come as you are' 5-10). ${ }^{20}$ Overall, however the franchise does not offer the degree of critical reflection on post-9/11 society offered by Law \& Order.

The increasing techno-intelligence of criminals and the complexity of their crimes in our surveillance society is, however, not overlooked. Both franchises demonstrate that criminals have access to technology and knowledge of forensic science. Implying that we live in a post-panoptic society, where it is not only the few watching the many, but also the many watching the few, a reality permitted by the horizontal expansion of surveillance technology, the accessibility of information is frowned upon by the detectives. The programs struggle with the way in which top-down notions of surveillance are becoming obsolete with the advancement of technology. The franchises imply that we have gone beyond the panoptic, to a society that grants anyone, who is willing to pay for information and technology, the access to observe others and to record their observations.

As Mathieson's (1997) 'Viewer Society' essay demonstrates, the change in today's society allows for the democratic use of surveillance, giving the many the power and access to watch the few. Although Mathieson approaches this as going beyond the top-down approach to surveillance culture, the two franchises note its possible risks. In

\footnotetext{
${ }^{20}$ Originally aired 27/11/06.
} 
Law \& Order such themes as identity theft, (Law \& Order, 'Identity'14-6) ${ }^{21}$, the selling of personal information by companies (Law \& Order, 'Access Nation'12-15), and the increasing demand for Reality TV help foster the sense of 'the many watching the few'. In both 'Swept Away' (Law\& Order, 11-15) 22 and 'Public Service Homicide' (Law \& Order, $17-5)^{23}$, Reality TV becomes a sub-plot to a murder. In the latter episode, McCoy notes how journalism has changed; reporters no longer report a fight, but set one up and then report it. When he questions the producer of a reality show, she argues, "I'm a producer, a journalist, not a criminal", to which McCoy responds, "Journalists report the news, but you create it". The episode depicts the way in which access to information has increased the media's propensity to take the law in their own hands rather than leave it to the police and the legal system. As well, the episode negatively portrays the fascination that people have in watching others; "If people want to watch a man crawl through a tunnel full of rats, I can only shake my head" (McCoy, 17-5).

In Law \& Order: SVU, the post-panoptic is demonstrated through both the knowledge that criminals have gained, and the access to surveilling power they have been granted through technology. In 'Criminal' (Law \& Order: SVU, 5-21) comprehension of forensic science and his awareness that there are cameras everywhere, allows him not to self-regulate, but rather to carry out the perfect crime by framing someone else. As well, as is evident in the episode 'Choreographed' (Law \& Order: SVU, 7-9), knowing that the detectives will turn to bank records or phone records for

${ }^{21}$ Originally aired 5/11/03.

22 Originally aired 28/01/01.

${ }^{23}$ Originally aired 20/10/06.

${ }^{24}$ Originally aired 20/04/04. 
evidence, the killer frames the victim's husband by buying the poison that killed her with his credit card.

In the CSI programs, similar post-panoptic notions are demonstrated, whether this involves the emailing and text messaging of a mass gathering by citizens in CSI: Miami ('Murder in a Flash' $3-4)^{25}$, or addressing the increasing amount of voyeuristic internet sites ('Big Brother' 2-8). ${ }^{26}$ However, while acknowledging that surveillance technology is accessible by citizens through GPS locators, or camera phones, and even by using the footage of a crime taken by a bystander in 'Open and Shut' ( CSI: NY, 3-6) ${ }^{27}$ to solve their case, the franchise criticizes surveillance technology's wide-spread convenience.

With increased access to personal information and increasingly sophisticated technology, crimes have become more complex. Although this is visible throughout all three of the CSI series, it has become especially prominent in one ongoing storyline in the current season of CSI, in which Grissom receives, prior to each crime, accurate miniature crime scene models which foretell the impending murder. The modeled structures, which provide the details of the crime scene, are shipped to the lab as a clue prior to the discovery of the crime scene; Grissom's inability to solve the crimes, however, despite his extensive knowledge and the wide array of gadgets at his disposal, demonstrates the increasing "intelligence" of criminals. ${ }^{28}$

Despite the awareness on the part of both franchises that surveillance is no longer only top-down, or that it is not only State controlled, neither embrace the post-panoptic. Instead, they advocate for a return to the panoptic, where the police or investigators are

\footnotetext{
${ }^{25}$ Originally aired 10/11/04.

${ }^{26}$ Originally aired $11 / 17 / 03$.

${ }^{27}$ Originally aired $25 / 10 / 06$.

${ }^{28}$ The Miniature Killer strikes in 7 of the 24 episodes this season. The list of the episodes include 'Built to kill' part 1 and 2, 'Post Mortem', 'Loco Motives', 'Monster in the Box', 'Lab Rats', and 'Living Dolls'.
} 
the only ones who employ the latest surveillance technology or who have access to various databases. They foster this notion by exaggerating the risks that the advancement of technology may cause, which includes the possibility of technology falling into the hands of the disturbed, the criminal, or anyone else with privacy-infringing motives. However, when it comes to their own use of the technology, they legitimize its privacyinfringing methods by advocating its usefulness in calculating risks, in solving crimes, and in putting convicts behind bars.

Both franchises normalize the use of surveillance technology through the reaffirmation of its necessity to police work. Through this normalization, the invasiveness of technology is overlooked. As Poster (1990) notes, the idea of the 'superpanoptic' involves the agency of the subject, and this leads to people's participation in surveillance by sharing their own information through forms, loyalty cards, etc. However, the voluntary disclosure of information is problematized by Lyon (2002) and Gandy (1993, 1995, 2006), who discuss its potential for fragmentation and discrimination. As surveillance technology and its possibilities advance and become further integrated into society, its normalization leads to the sharing of personal information through participation in it, which can segment the population. Furthermore, as Gandy notes, the information collected increases the ability to identify risks. However, this exceeds technology's ability to intervene or correct these risks; rather, it discriminates in advance based on a data double rather than factual or physical information (Gandy 2006, 328).

The moral voice is also an important element of, and featured in, both franchises. Most evident in Law \& Order, Jack McCoy's strong moral values deliver the case despite the emotional dilemmas that might otherwise change his tactics. His assistant attorneys 
are most often the ones that become emotionally involved or morally confused, whereas McCoy's moral values drive his attitude, for which he is often accused of being heartless and lacking in empathy. In Law \& Order: SVU the moral voice is that of Captain Donald Cragen as the rest of the team invariably become emotionally involved in each case. However, his moral voice is also often under pressure from those above him in command, and by the public's demand for convictions.

In the CSI franchise, the moral voice differs from that of the Law \& Order franchise as the latter presents only one distinct character as the moral voice, while the former tends to portray a less morally centered narrative, suggesting instead that the lab and its detectives are all morally inclined to follow the evidence. Here morality is scientized, whereas in Law \& Order it is humanized. However, despite depicting it as such, there is at least one distinct character within each series that becomes the moral foundation for the team. Horatio Cane is the moral voice for CSI: Miami, but there is also a moral note in Calleigh Duquesne's behaviour, as she at times sacrifices her relationships in order to hold the moral high ground. In CSI: New York, this element is offered by Detective Mac Taylor, whose moral code is also very pronounced. In CSI, the moral voice undeniably is that of Gil Grissom, who in later episodes, does bend rules to protect his own crew, but still remains machine-like in his moral intractability.

The key difference between the two franchises is in how they differentiate between the relationship of humans with technology, and this resonates not only in how they approach the technology but also in how they convey the role of the investigators themselves. In $C S I$, the original series created robotic characters like Gil Grissom, an inflexible, unemotional perfectionist. His stern character and lack of emotions produced a 
completely objective analyst that could not be wrong in anything he pursued. Grissom has since changed to reveal a more emotional side to his two-dimensional character as a result of his relationship with Sara Sidle and his special bond with Dominatrix Lady Heather (Melinda Clarke). As well, his hearing loss in the end of season three has humanized him, showing flaws which in turn, further demonstrate the way in which the franchise views technology as the only neutral, flawless device. All humans eventually succumb to physical or psychological weakness.

The rest of the CSI franchise broke these ideals, depicting the intelligence and disciplined nature of their investigators, but also demonstrating that the human senses are overshadowed by the emotional and personal ties that prevent one from being completely objective. In CSI: Miami, Cane's emotional tie to his brother's family and to the victims he faces helps drive his cases, but also highlights his flaws. Although he promises to solve the case and put the suspect behind bars (eventually delivering on this promise), his emotional involvement in the cases are not ignored and complicate their efficient disposition.

In CSI: $N Y$, the machine-like Det. Mac Taylor is demonstrated as just that, machine-like, but this is not conveyed as an element of his core personality, but rather the way in which he deals with his wife's death. The rest of the team also faces emotional issues, whether these are problems in love, in dealing with abusive partners or with the emotional crisis of being diagnosed with AIDS. These sub-plots help humanize the team despite their close relationship with technology, tempering their reliance on technology and forensics alone to produce knowledge. 
In the Law \& Order franchise, the characters are represented as more morally flawed than those within the CSI franchise. Their shortcomings, and the impact of the detectives' and A.D.A.s' personal lives and histories on their work, are expressed in the degree to which they become emotionally attached to the victims. There is no flawless character in any of the three series; no one possesses a robotic nature that would set them apart from the victims or the suspects. The investigators and D.A.s are not represented as a form of technology. An example is Elliot Stabler, who on a number of occasions, encounters suspects who tell him that he is no different than they are, and who has admitted to wanting to kill the suspects he brings in. As well, the issues of divorce, family problems, addictions and so on, are all dealt with, providing an emotional resonance when the detectives face similar cases to their own experiences. Hence, the detectives in the Law \& Order franchise are much more humanized.

Surveillance is however taken up in both franchises as morally inflected, yet the moral stance is linked to state authority. When surveillance is mobilized by the population, it is risky. The overall concept that the franchises convey, is that the proper control of technology should lie in the hands of the State. The rhizomatic access to information and employment of technological devices in the post-panoptic society is framed as morally problematic. Instead, the State's use is the moral one. The surveillance discourse in the Law \& Order franchise tells a cautionary tale, suggesting that surveillance society is not black or white, but rather characterized by shades of grey, depending on in whose hands the technology lies. Hence the moral stance taken deals not with the technology itself but rather its location. The important question then shifts to: who is using surveillance technology? In the post-panoptic society, risks are reasserted in 
a moral language which functions to reclaim the bureaucratic control of the top-down model, the return to the panoptic.

Law \& Order specifically acknowledges that the institution of justice and its agents are flawed, a notion conveyed not only through the personal lives of the police detectives, but also through the sense of injustice expressed when the guilty party is acquitted because of the shortcomings of the detectives or the A.D.A.s. By establishing and recognizing the flaws in human nature through its moral discourse, the franchise frames technology as a positive force which helps extend the role of the witness, and of the detectives. However, as agency is situated in the human subject, rather than in the surveillance devices or forensics, the agents' own flaws become a problem. The series thus suggests that surveillance society at large is, at best, flawed. Law \& Order insinuates that to carry out justice, the technology should be in the hands of the State, through the police. However as the franchise embraces the top-down model, it also recognizes that the model can be flawed, thus further fostering the notion that despite the convenience of technology, it does not promise a risk free society.

Further demonstrating problems at the top, the conflicting nature of the institutions of justice within the moral cautionary tales of the Law \& Order franchise is affected by the pressures of politics. The Bureau Chief and D.A.s are elected officials, representing political interests, and therefore must follow certain guidelines despite their conflicting moral judgments. When a high profile case transpires, and when there are reasons to give out plea bargains, the decision becomes conflict-ridden for the district attorneys, as their own expert opinions are overruled by the interest of politics and upcoming elections. 
In the CSI franchise, the institute of justice is left invisible and assumed, since the prosecution of cases happens after the episodes end. The exclusion of evidence is not addressed; only very rarely do we see guilty suspects potentially being acquitted based on the errors of the scientists and investigators. The naive and idealist perspective of the franchise suggests technology should reign over human frailty. The franchise demonstrates that while people can be flawed, science is not. Through technology, the investigators can better control against the risks of society. The moral narrative active in all three series within the franchise promotes a top-down model of control, but unlike the Law \& Order franchise that sees the top being flawed, the CSI programs see technology as neutral and thus believe that despite human flaws, technology will ultimately get at the truth. The moral tale they create and foster deals with the virtuous nature of technology, and how it helps manage risks in society. The panoptic notions of security and convenience are thus promoted.

As surveillance narratives, both series situate their characters and events solidly within surveillance society. Both embrace state control over surveillance technology and posit risks from the inevitable democratic elements of ubiquitous technology. However, while sharing certain elements such as surveillance narratives, the two franchises also suggest very different understandings of how technology and human subjects do, and should, interact. They offer very different epistemological frames as they seek "the truth". These differences reveal interesting issues about how we understand bodies and subjects in surveillance society and will be discussed at length in the following two chapters. 


\section{Chapter 3}

The Old Fashioned Way: Reclaiming the Human Subject in a Post 9/11, Post-Panoptic Surveillance Culture

What the eye can no longer see, the ear cannot hear, or touch cannot feel, or even when the senses appear to deceive us, these instruments perform like a new sense with astonishing precision. (Quoting Etienne-Jules Marey, in Seltzer, 1992, 16).

Living in a risk society, we face the human shortcomings of detectives and district attomeys, the pressures of politics, the potential for crime and victimization, and the flaws in both individuals and the justice system. The Law \& Order franchise portrays and partially contains the fear of this risk society by solving serious crimes. The moral discourse of the programs extend beyond their crime drama narratives, and beyond the reoccurring characters' personal lives, to the impact that surveillance technology has had in the post-panoptic risk society. I argue that the relationship between technology and the human being offered in Law \& Order is one of prosthesis. The idea of prosthesis posits technology as an enhancement of the human body, supporting the characteristics of human beings, of their capacities, and improving upon them. The prosthetic discourse figures the human subject as always lacking, as an incomplete witness, but as one who can be completed with technology, through the extension and perfection of their abilities. This chapter will discuss prosthesis and its primary elements, and how it manages to enhance the agent, the human subject, rather than replace it. Law \& Order's dominant narrative on surveillance frames technology as prosthesis, always referring back to the human subject as the witness. Technology only extends and enhances the human agency of the witness. The elements of prosthesis I focus on include the technologies that enable seeing and matching which in turn, provide the enhancement of experience and memory 
in the act of witnessing. In other words, surveillance technologies are used as a supplement to the limitations of "man", as a form of enhancement to the black box of our senses. The prosthetic discourse asks: can surveillance technology supplement the witness as a reliable source, or act when there is no witness? How does surveillance technology address that lack? In what ways does technology serve as prosthesis for the human body?

The term prosthesis is most commonly referred to in its use as a medical term to denote the substitution of an artificial body part for missing limbs, in other words as the actual extension of the body by artificial means (Jain 1999, 32). However, the term can also refer to the virtual extension of the body by communication media. Marshall McLuhan, in Understanding Media: The Extensions of Man (1964) uses the concept of prosthesis to explain media's function as 'any extension of ourselves' (McLuhan, 7). According to McLuhan, just as clothing is an extension of the skin, electric technology is the extension of the central nervous system. McLuhan notes that media, as it extends, also amputates, referring to the process as 'autoamputation' (McLuhan, 43).'

When attempting to explain prosthesis, scholars often look to Henry Ford's assembly line model. Ford (1923) states that the assembly line helps explain the ability of prosthesis to extend human capabilities. Relating machinery to prosthetics, he draws a connection between an assumed deficiency within the amputated human body, and the compensation supplied by man-made machinery, confirming that human capabilities may fall short, and require technological devices to assist in accomplishing the task at a faster pace. Efficiency as a goal is thus radically enhanced by prosthetic labouring technology.

\footnotetext{
${ }^{1}$ He again emphasizes the idea that the media are 'extensions' of our human senses, bodies and minds in The Medium is the Massage: An Inventory of Effects (1967) by readdressing the arguments presented in the Prologue to The Gutenberg Galaxy.
} 
Yet this carries the risk of alienation. As Karl Marx's (1867) description of the connection between material things and social relations indicates, the blurred line between men and the materiality of the commodity sets up a prosthetic system in which social relations are determined by the material relations between humans and commodities, ultimately alienating men from one another and from themselves (Marx, 77).

Jacques Derrida (1967) also adopts the notion of prosthesis and refers to it as 'the supplement", employing it as a neutral concept that "signifies nothing, simply replacing a lack" (Derrida, 921). Derrida does not use the supplement as a device for separating the artificial and the real, but rather as a concept that is inseparable from existence, and in which many seeming oppositions collapse together. His student, Bernard Stiegler, also highlights the doubled nature of prosthesis as extension and amputation, claiming that it is a "supplement, marking the default of the origin... [that it] does nothing but try and fill this default in: and yet, in doing so, it can only affirm it as necessary" (Stiegler 2001, 260).

An interesting approach to understanding the relationship between the body as animate and technology as inanimate object is that of Mark Seltzer (1992) who examines prosthetic technology in the Industrial Age. Focusing on the end of the $19^{\text {th }}$ century, Seltzer refers to Thorsten Veblen's 'machine culture' and the 'American body-machine complex'. Taking up the 'writing machine', he notes that the machine has not replaced the body, nor have bodies become machines, but instead that bodies and machines are radically and intimately coupled (Seltzer, 13). Seltzer notes the repetition and speed that place the body in the position of 'movelessness', as exemplified by the machine workers, 
forcing the body and the nerves to work automatically and apart from the worker's own volition (Seltzer, 13); it is this relationship that is of ultimate interest to Seltzer. Using Jack London as an example throughout the book ${ }^{2}$, Seltzer claims that the relationship between body and technology, as London types on his typewriter, does not demonstrate the demotion of living body to the machine, but their intimate correlation (Seltzer, 14).

Seltzer employs the typewriter to imply that the machine becomes a mechanical inscription of the body, written and deciphered by technology; the writer's typed words, therefore, do not reflect the writer's desire but the prosthetic language of the body and the mechanical and automatic inscription of the body's force (Seltzer, 16). Seltzer perceives technology as prosthesis, demonstrating both the distinction between technology and the body, the former supplements a lack in the latter, as well as the possibility that the senses can be deceived, requiring technology to function where the body cannot. Approaching the relationship between man and machine, Seltzer notes that technology is a line that crosses nature, or allows for nature and culture to meet (Seltzer, 18); however, this mobilization between the two results in a violation of agency which he refers to as the erosion of boundaries dividing person and things (Seltzer, 21).

The linking of hand, eye and letter in the act of writing by hand intimates the translation from mind to hand to eye, and hence from the inward and invisible to the outward and visible. This process exhibits the transition from nature to culture (Seltzer, 10). Seltzer states that this dislocation results in standardization and a broader logic of prosthesis. He notes that the typewriter was for the blind what the telephone was for the nearly deaf, and refers to Ford's assembly line as being for the armless and legless

\footnotetext{
${ }^{2}$ Seltzer refers to a series of literature around boyhood, and the making of men which includes the bestselling 'wilding' stories of Jack London (Seltzer, 4)
} 
(Seltzer, 10). Ford's application of technology as a tool to help the disabled to work on the assembly line demonstrates a transcendence of the natural body and an extension of human agency through the forms of technology that represent it (Seltzer, 157). The progression of prosthesis becomes the ideal and collapses time and space by connecting conception, communication and execution (Seltzer, 11). To Seltzer, this is the double logic of prosthesis and culturalism, the idea that the individual is something that can be made (Seltzer, 157).

Donna Haraway (1991) approaches the notion of prosthesis somewhat differently; from the insertion of RFID chips to the common use of heart monitors and contact lenses. In her theoretical understanding of 'cyborg anthropology', she explains that the fusion of machine and body is a creature of social reality (Haraway, 149). To Haraway, in the "late twentieth century machines have made thoroughly ambiguous the difference between natural and artificial, mind and body, self-developing and externally designed, and many other distinctions used to apply to organisms and machines" (Haraway, 152). In other words, technological advancements in surgical prosthetics push boundaries between the body and prosthetic devices to the point that the (natural) body becomes indistinguishable from the (artificial) prosthetic. The cyborg literature that Haraway employs to address both prosthetics and notions of gender and race in the post-modern world includes the categorization of the cyborg as restorative, normalizing, reconfiguring and enhancing (Gray, Mentor et al. 1995, 3), all of which, in general, denote the enhancement of the body.

Haraway's theory of prosthetics raises the problem of the 'self' and agency as she states that "the proper state for a Western person is to have ownership of the self, to have 
and hold a core identity as if it were a possession" (Haraway 1991, 135). She claims that possession is something that one can either be born with, or that one can make from various raw materials over time as a result of cultural production; however, "Not to have property in the self is not to be a subject, and so not to have agency" (Haraway 1991, 135). The possession of the self to which Haraway refers explains that the human subject is stripped of its 'self' when it loses its property through the process of being scrutinized by a mediating gaze. Surveillance technology as prosthetic to the body tends therefore to result in the loss of agency, as the body is altered from its natural to artificial state without being able to distinguish the two.

In my analysis, the human capacities and senses that I have chosen to demonstrate prosthetically include 'seeing' and 'tracking' which involves the skills of matching and human memory. Both are enabled bodily features that surveillance technology enhances when one is unable to see, or when one's ability to do so is limited. That which is not experienced by an eye-witness creates a sense of the unknown, of uncertainty. What happened, and how it happened become questions that we may turn to surveillance technologies to answer. The elements of enhancement, agency and alienation that the prosthesis literature emphasizes, can be adopted to explain why we question the sensory experiences and observations of human subjects and how surveillance technology should be approached.

\section{Prosthetically Enhanced}

The idea of technology 'seeing' in surveillance society is often evidenced with Closed Circuit Television cameras (CCTV), technologies initially implemented to 
monitor, track and encourage self-regulation, and have since become highly embedded in the security driven dialogue of today's society. As well, we increasingly enhance our sight with the use of cell phone cameras to record witnessed events. The post-panoptic understanding of 'seeing' has shifted from the watch-guard to that of a more democratic application in which the many watch the few. Furthermore, with the increasing access to technology, technology has altered the everyday experience of 'seeing' (Mathieson 1997).

Tracking is a broader category of human capacity which combines elements of memory and matching. Matching is the ability to make sense of data collected and through recognizing patterns, to transform it into information. The ability to process data and make sense of it comes from experience and skill; however with the amount of information available in our society effective processing becomes impossible. The human mind cannot store and manipulate all the information unaided. The enhancement of the mind, of memory and of storing and making sense of information, is thus achieved with the use of databases that extend matching ability, allowing for various variables to be compared across different data sets.

Seeing and matching are vital for investigative work, but are also necessary elements in witness testimony. The witness is one that shares what she saw; speaking for the Other who is absent. The witness also matches suspects to memory, picking the suspect out from a line-up. However not all witnesses are 'reliable'. The problem with traumatic events is that whether one is a witness to the crime or its victim, one's vision and memory may not be clear, diminishing the chances of finding the suspect and 
convicting her/him. The role of the witness is thus enhanced by the use of technology in order to produce "truth" within the prosthetic discourse.

The nature of the witness has changed, modified to meet the current technological advancements in surveillance and forensics. Witnessing used to be the act of speaking or writing what one saw with one's own eyes and hence the act of witnessing defined one as a human subject. Furthermore the witness speaks for someone other than him/herself, making a claim for the absent and the bygone. As Primo Levi states, witnessing occurs only when one is heard speaking out for the Other. From this understanding, witnessing requires a subject who has seen or heard the event to be willing and able to speak for the victim. However, Law \& Order's prosthetic discourse poses the question - what do we do if there is no witness or if the witness did not see or cannot speak? It argues that technology may be usefully deployed to enhance human subjectivity in the pursuit of truth. To apply the notion of prosthesis is to define the lack. This lack may include the story of, or memory of the witness, or the questionable validity of the witness. Surveillance technologies and related forensic science are hence adopted and applied in Law \& Order to help extend the human body, and thus the role of the witness. To argue this point, the examples employed can be broken down to explain technology's enhancement in witnessing, the problems of witness intimidation and the duality between technology's enhancement and the risks of alienation when the technology is used democratically.

The premise of Law \& Order resides in the notion that traditional detective work can get at the truth through weaving together the various threads of stories provided by witnesses. Interviewing people who knew the victim leads the detectives to others who, 
in turn, help create a timeline, produce a motive, and identify a suspect. The subjects may have witnessed the crime, they may have found the body, or have known the victim; regardless of their implication in the events, eventually their story is confirmed or rejected. The Law \& Order franchise toys with the notion that people may lie to hide something or to protect someone; however the live subject as the witness remains necessary.

Despite the central role of the human witness in Law \& Order, surveillance and forensics do play a role. This is most prominent in the $S V U$ series, as its storylines acknowledge the infiltration of surveillance technology and the changes made in privacy laws, post 9/11. The use of surveillance however, functions as a supplement to the witness, and to the investigative work that is done through traditional means of sketches, line-ups and K9s. Access to surveillance cameras, or EZ passes, help further the investigation but are again used as an extension of the witness, compensating for what they did not, or could not, see. Technology does not replace the witness as the source of truth, it enhances the witness's capacity to see, to make sense and to tell. The Law \& Order programs not only place value on the psychological analysis of suspects, but they also reflect a moral dilemma that focuses people's perception of technology, of society, of law and of order. The franchise tends to put the legal system, surveillance and witnessing on trial as much as it does criminals; the programs address issues that deal with women's reproductive choice, stereotypes of Muslims, and fear of terrorism post $9 / 11$, for example. 


\section{Technology as Witness Versus the Risks of Technology}

Providing examples from the seasons upon which I based my analysis, I draw out technology as prosthesis by understanding that prosthetics deal with enhancement, agency and alienation in a human-centric society that both contains too many frailties and requires the construction of truth. Despite access to an abundance of information, the use of that information as an extension of the witness, which attests to the truth claims afforded to surveillance, becomes the basis for the programs' use of surveillance technology and forensics. The $S V U$ episode titled 'Head' $(5-25)^{3}$, deals with two rippedfrom-the-headline stories, one being the 2000 Virginia case in which a man sexually molested his stepdaughter because of a brain tumour, and the other resembling the Mary Kay LeTourneau case in which a teacher engaged in an inappropriate sexual relationship with a student. These two stories are combined to form the sexual assault case that the episode revolves around. As SVU's dominant narrative deals with surveillance, the episode allows for the story of the assault to unfold as a sub-plot that only later, with the use of surveillance, becomes the main story. The initial case, however, begins with a video voyeur's hidden camera in a public restroom. A young girl discovers the camera, calls the police, and the SVU team arrives at the scene. Stabler and Benson, upon finding the camera, discuss the dangers of the wide accessibility of technology in today's society.

Stabler: "It's become to easy to invade someone's privacy."

Benson: "Yeah, now you can violate somebody from sitting in front of the computer and enjoying a cup of coffee."

They set out to track down the 'perp', by tracing the surveillance camera to the certain store in which it was designed, and accessing its customer list to find the individual that

\footnotetext{
${ }^{3}$ Originally aired 18/05/04.
} 
had ordered the exact model. The database holds the personal information of each buyer and the products they purchased, hence when it comes to matching the camera with the list of buyers, the database is the technology preferred over the store clerks' memory. When it comes to tracking the suspect, the detectives use surveillance databases as an extension of their senses and those of other potential witnesses, helping to enhance their search. Ironically, they view their own use as different from what the 'perp' did. Yet it is unclear within the episode's narrative just what those differences might be, and the nature of the checks and balances, if any, which are placed on official use of surveillance and data banking technologies. The episode also legitimizes technology as a security tool, as the spy camera seller notes, "You name it, we can put a camera in it. Who knows how many lives it has saved". In this circumstance, the "eye' becomes the camera that is now secretly placed not only to cause the self-regulation of behaviour, but as a strategy of protection given to anyone that requires it. It is lauded as a measure to save lives, without any clear reasons provided as to the way in which it does this.

Once the 'perp' is tracked down, he decides to provide the detectives with information regarding another crime that he has caught on tape, in order to negotiate a lesser charge. His spy camera at a different location had caught a person sexually assaulting a young boy. The story then turns from the privacy infringing nature of surveillance, to the more laudable purpose of using the video to solve a new crime. The recorded tape thus provides the crime, the suspect in the rape, the victim, the location, and a description of what they wore. It becomes witness to the crime, seeing and reporting what the victim did not. It extends the observation of a crime and provides the description to track the offender; the technology alone, however, does not solve the case. 
The video provides the detectives with a lead to follow, but their next step in solving the case involves traditional means of getting at the truth. This includes their numerous interviews with the boy's mother, the victim, and later with the suspect's stepson and husband. Despite the fact that the case is solved through conventional detective work, the extended sensory information from the video footage ends up legitimizing surveillance, containing and limiting the initial negative criticism expressed regarding surveillance technology. The video is thus depicted as essential in seeing, to uncovering the case, while the discourse questions the way in which technology is employed. It frowns upon its privacy-infringing nature when it is in the hands of the wrong person, a citizen who could be a criminal, but highlights its significance in police work as a prosthetic tool to reveal what was not seen. In this way, as Stiegler suggests, the prosthetic fills a default and in doing so, is affirmed as necessary.

In another example, when a famous baseball player is killed with a bottle in a bar fight, the detectives realize that the murder was planned by an angry fan who blamed the player for throwing the game and losing the World Series (Law \& Order, 'Vendetta' 1421). Investigating the player's life, the detectives come across a website 'www.getdonner.com', and under 'Donner Watch', it provides up-to-date information on the victim's whereabouts, his home address and his phone number. The detectives frown upon the privacy infringing nature of the website, noting the dangers of people's access to information which allows for the targeting of individuals, but they end up turning to a database to match the fingerprint on the bottle and to track down the suspect. Again, by helping track down the suspect, the database is affirmed as necessary, while the use of surveillance technology by citizens is demonstrated as risky.

\footnotetext{
${ }^{4}$ Originally aired 21/04/04.
} 


\section{The Risks of Accessibility}

The prosthetic discourse of the witness further permeates the programs' other series. Law \& Order looks at the problems resulting from 'rhizomatic' accessibility, demonstrating this issue through the rise in identity theft crime. In the episode 'Identity' (Law \& Order, 14-6) ${ }^{5}$, a man, Hitchen, is found murdered shortly after depositing $\$ 400,000$ in his savings account. As the detectives investigate the source of the funds, they realize that the victim ran an identity theft scam which left an elderly man homeless and impoverished. This scenario is discovered entirely through the investigative work of Green and Briscoe, who begin by questioning the victim's wife, and follow-up at his workplace, only to discover that he has been unemployed for over eight months. As the victim had a 'clean' record, and as no weapons were found, the detectives assume that the motive behind the victim's death was the money. Green and Briscoe go to the bank to examine the victim's transactions, which leads them to more people but ultimately to Lonnie Jackson, the man whose name appears on the certified cheques. Reinforcing detective work, Det. Green states 'No witnesses; nobody heard anything; everybody was at work”, Briscoe replies, “That's why I don't retire."

A surveillance camera placed in a post office, however, fills the gap left by human witnessing. The footage shows the victim at the post-office with a mailbox under Jackson's name. This confirms the detectives' contention that the murdered victim had stolen Jackson's identity and leads them to look for the real Jackson. Surveillance technology is figured as prosthetic rather than panacea, as prosthesis plays a minimal role, and the detectives try to gather information by turning to Jackson's neighbourhood for answers. As Briscoe states, "Nice thing about neighbours is, everyone knows

\footnotetext{
${ }^{5}$ Originally aired 5/11/03.
} 
everything about everyone else". The human witnesses then guide the detectives to Jackson's son who says he bought his father a computer. The detectives then turn to the forensic lab to track down the IP number and location of the email Jackson sent his son, and this allows the detectives to find Jackson.

The ease of collecting information and matching records to target an individual with the use of databases provides an enhancement to the human skills of tracking and matching; however, it is also this helpful tool, as the detectives discover, that helped Jackson locate Hitchen and take the law in his own hands. Jackson admits to receiving a spam email offering a million dollars which he filled out and replied to. He did so with his full name, allowing Hitchen to access Jackson's social insurance number, steal his identity, and put a mortgage on Jackson's house.

The form, which Mark Poster (1990) refers to as the structure of participatory surveillance in the post panoptic world, is the new alteration to the 'all-seeing eye of the watch-guard'; despite its democratic use, however, it is risky in that the information you disclose may be employed for purposes other than those expressly declared, which further exemplifies the problems and unintended risks of disclosing information (Calhoun 1992). In the episode, Jackson claims that once the bank took his home, he realized the problem originated with the email, and so he tracked the email address and found Hitchen's home address. Therefore, although Law \& Order demonstrates surveillance 'matching' technology as useful for tracking suspects when it is in the hands of the police, it is problematic when citizens have access to the same information. Executive D.A McCoy says, “It's a shame Mr. Jackson, no its despicable... hell its unconscionable. Andrew Hitchen stole your name, your property and your life savings. He should be 
sitting across the table right now, but unfortunately you took the law into your own hands and made that impossible".

The problem of identity theft is a social problem caused by technology, and yet it is here used to advocate the need for more surveillance. The moral issue of the episode speaks to both the accessibility of information in the Information Age and the vulnerability of those who are new to the technology, unaware that the information they disclose, even if participatory, becomes public and can be used against them. Although this is a negative characteristic of the technology, the episode simultaneously conveys surveillance as useful for police in enhancing witnessing, reinforcing a top-down model of surveillance.

In another example, a known D.A. is found stabbed to death. As the detectives investigate his murder, they discover that despite his twenty-year career and his reputation as a great D.A., he was a fraud. Stealing another student's social insurance number and identity, the D.A. never graduated from law school, but had fooled everyone, even McCoy. Although the identity theft occurred years before the advancement of technology or technology's omnipresence, the reference to identity theft is discussed to argue that with today's surveillance technology, and the increasing ease of this form of crime, identity theft has become almost inevitable (Law \& Order, 'Nowhere Man' 1419). ${ }^{6}$

\section{Agency: Forensics Versus the Human Subject}

Although the Law \& Order franchise introduces surveillance technology and further employs such technology to assist and enhance the detectives' work, it also tends

\footnotetext{
${ }^{6}$ Originally aired 31/03/04.
} 
to question its accuracy as relatively new technology. The series hesitates to legitimate the technology over the witness, at the same time that it demonstrates that the human subject is an imperfect witness. As human motives to lie are undeniable, the programs attempt to demonstrate the way in which neither the human witness, nor the technowitness, can be given total authority, and the fact that detective work should not be fully replaced by its prosthetic counterpart. This conflict is demonstrated in SVU s 'Escape' (5$11)^{7}$, in which the case involves a convicted pedophile who is desperate to prove his innocence before his ill mother dies. The convict escapes from prison after serving eleven years for a crime he claims not to have committed, even though it is his stepson who is the accuser, and a DNA match corroborated these accusations.

The story unfolds as the news of the convict's escape becomes public and the Special Victims Unit must find the man before he strikes again. The team splits in two and they interview his mother, who still keeps in touch with him, his wife, son, stepson and the stepson's wife. With the help of a store clerk as a witness, the detectives trace the convict's whereabouts. The case then turns into a hostage situation when the convict kidnaps his accuser to force him to recant his story. Once Benson tracks down the convict and his stepson, she also becomes a hostage.

The FBI gets involved and turns to surveillance cameras and wire-taps to monitor the motel room in which the convict holds his two hostages; however, the police department allows Benson to negotiate with and disarm the convict. The camera helps witness the sequence of events in the room, to monitor for undue risks that may occur, but it is not the technology that ultimately resolves the issue, but Benson's negotiating skills. As the conversation unfolds, Benson begins to believe the convict's story.

\footnotetext{
${ }^{7}$ Originally aired 2/12/03.
} 
Afterwards she reviews his case and uncovers the web of corruption and deceit which, combined with the unreliability of DNA testing ten years ago, led to his wrongful conviction. At the end, Benson helps reunite the convict with his mother and the son he never met.

The narrative revolves around the defects of technology, the problems of relying on DNA testing alone, and the inevitable corruption and human error of the justice system. It also deals with the flaws of human nature and the motives that lead them to lie. The stepson was being assaulted by his uncle, but due to their small difference in age, he thought it would be interpreted as consensual, so he blamed his innocent stepfather. Although DNA test results had put the convict in prison eleven years ago, the show undercuts the possible critique of DNA testing by using the very same technology to ultimately prove the convict's innocence. DNA as a technology is portrayed as having progressed and overcome some of its initial unreliable attributes. The DNA test results prove the uncle as the guilty party and these findings force the accuser to admit to the truth. The technology induces the victim, who is also a witness to the crime, to tell the truth.

Although this episode relies on the progress of technology, the DNA results ultimately function as a confirmation of Det. Benson's instincts. The tests are only a measure to finding the truth, an extension of the subject's word. In the current social context, although the technology may be necessary, its work is to supplement human skills and attributes.

Although DNA is the ultimate-surveillance technology, there is a relative absence of it in the Law \& Order franchise. It does not have a central space or a determinative 
role in the two series as the detectives rely on interrogation and their investigative skills to uncover motives, and the D.A.'s focus on eye-witness testimonies over surveillance, in convicting a suspect. When DNA testing is employed, its risks are also revealed, further demonstrating the franchise's irresolute stance for the human subject.

The questionability of DNA is also addressed in 'Vendetta' (Law \& Order 14-21), where a man is sent to jail for twenty years for a crime he did not commit. Initially, the police found a bloody knife in his apartment, and due to the infancy of forensic technology, it was tested for blood type alone. After a match, it was assumed to be the murder weapon. When the man is charged for another crime after being released, the suspect's lawyer argues that it was prison life that made him a killer. As the detectives attempt to build a case against the suspect, they begin investigating his life only to find out that the police officer who found the murder weapon twenty years ago was also the police officer who had charged the suspect for another crime, a convenience store robbery. Despite the store owner's testimony that the suspect was not the one that attacked him, the officer insisted. Upon discovering these facts, Briscoe and Green realise that the police officer had a vendetta against the suspect and had planted the knife to get back at him for an earlier crime that the officer had accused him of committing. Hence, both examples convey the risks of relying on DNA alone and the problems of turning to forensics over the human subject's own testimony. In the end, through constructing the truth, the investigators realise that the live subject's word holds more validity than the technological witness; however, as DNA test results are highlighted as being irrefutable in court, the detectives return to it as a tool to further enhance the witness's testimony. 
The problem with human subjects is that whether they are the suspect or the victim, they may have a motive to lie, or trauma may have affected their memory of events. In such cases, surveillance technology becomes an enhancement of the witness. Despite its utility in extending the witnessing of the crime, its importance to a case and particularly to winning a case, is not as clear cut as the discourse on surveillance argues. Law \& Order demonstrates that despite the various technologies available which enhance seeing and data matching, the law has yet to catch up to this technological progress and thus surveillance evidence can be excluded from a case. In Law \& Order 'Payback' (14$12)^{8}$, the judge excludes the wire tap placed on a mob leader and suggests to McCoy, "You have to prove your case the old fashioned way, the wire is gone". The episode also reinforces the importance of an eye-witness as evidence collected through surveillance does not result in the same credibility that is given to the live witness. McCoy states "I can make all the coincidences and evidence add up, but at the end of the day, we don't have any eyewitnesses".

\section{The Role of the Witness in Law \& Order}

The witness is present in each episode of the Law \& Order franchise, whether it is the witness that finds the body, the body itself, the witness on the stand, or surveillance technology functioning in that capacity. The latter, however, is treated as an extension of the human witness, of the victim's word and of the investigator's findings. Although surveillance technology helps, it does not replace human agency. Rather, it enhances seeing, profiling and matching. As stated above, the witness is a truth producing agent,

\footnotetext{
${ }^{8}$ Originally aired $14 / 01 / 04$.
} 
however witnesses are notoriously unreliable. In Law \& Order 'Can I get a witness' (14$16)^{9}$, the problem of witness intimidation is explored.

The episode deals with a shooting to which there were two eye-witnesses. The witnesses are used to identify the suspect from a line-up, which ensures that they are accurate and consistent in their stories. In the prosecution segment, McCoy attempts to confirm that the witnesses are credible, asking Southerlyn to check on their background, "Teenagers: you never know how they will hold up in court, but better make sure no drug angle". The importance of the witness testimony is made clear when the suspect's lawyer states, "Looks like your two witnesses are your whole case". However, when one of the witnesses backs out and the other is shot after his testimony, but before he can be crossexamined, the case turns to focus on the issue of witness intimidation. As McCoy argues, "The murder of witness threatens the foundation of our judicial system". In the end, the second witness changes her testimony on the stand, while admitting behind closed doors that the suspect threatened her and offered her a payoff; the jury finds the suspect not guilty and the prosecutors lose their case. The episode highlights the complicated relationship between witnessing and truth in the justice system. As well, it demonstrates the flaws of the judicial system because it is necessarily human. Technology cannot be intimidated or bought off. Therefore justice seemingly requires a combination of human and machine testimony.

The flaws of human subjectivity and the justice system are further demonstrated in both 'Embedded' (Law \& Order, 14-8), and 'Patient Zero' (Law \& Order, 14-3). In the former, a journalist sets-up his own shooting to prove a point about the State's involvement in the reporting of the Iraq war, while the latter demonstrates the importance

\footnotetext{
${ }^{9}$ Originally aired 25/02/04.
} 
of testimony when a suspect is not convicted of spreading SARS because of his wife's word on the stand. His wife exploits the sympathy of the jury to put on a show, crying about her husband's adultery. Thus, by continuing to claim she was with him at the time of the murder, to be his alibi despite her pain, her lie is perceived as truth and as a result, her husband is acquitted.

\section{The Body as Witness}

In surveillance society, the body becomes a source of information that is unique to each individual: this includes DNA, fingerprints, face geometrics, and so on. Each touch of a body, each strand of hair, and each skin cell leaves traces of itself from which the identification of a complete subject can be made. This information that is unique, private and embedded becomes public and scientifically mediated; it is granted legitimacy. The DNA left behind at the crime scene exemplifies disembodiment through information, and is irrefutable. The body's unique information permits access to many, while closing doors to others (Gandy 2006). The body becomes a source of information, whether we look at it as the body itself, the information that it leaves behind, or that it holds on its surface. The body as traces of disembodied elements can also, therefore, witness. It produces truth and informs in the absence of other knowledge.

In this way, the victim's body also functions as witness, providing information, which once interpreted by technology and science, becomes truth. What lies on the medical examiner's table can be the victim, but it can also be read as the witness. The bruises, the stomach contents, blood, and time of death become information, enabling the 
examiner and detectives to create a time-line of the victim's death, identify the location of the crime, and ascertaining the victim's state of mind at the time.

The body in the Law \& Order franchise is rarely emphasized for its witnessing potential alone, and thus rarely does the body get instantly sent to the coroner. In fact, the franchise tends to view the body as a victim rather than approaching it as disembodied evidence. The victim's body, when found, initiates the gathering of information about the victim, from identifying who it is, to where the victim worked, to his/her family, to the parties involved in its murder. The victim's body is viewed as a formerly embodied person. Hence although forensics plays a role in the franchise, the victim's body is not interpreted as the witness.

Although the body is not perceived as a witness within the narrative of the franchise, but rather as a victim, the significance of the body is still brought to our attention when we consider the way in which the body can testify against criminals and their ever-increasing expertise. Criminals now take extra measures to ensure that bodily fluids, fingerprints, etc. are wiped clean, to erase the evidence that could lead back to them. An interesting plot-line in Law \& Order: $S V U$, explores the knowledge that crime analysis provides and the use of that knowledge, by criminals to commit the perfect crime. In 'Criminal' (Law \& Order, 5-21) ${ }^{10}$, the episode begins with a flower-seller discovering police tape around a crime scene. He reports it to the police in order to accelerate the investigation, as it is hurting his business. When the police realize that the yellow tape is not their doing, they discover that an offender had taped off the murder scene in order to buy time. The dead woman's body is discovered and sent to the medical examiner who concludes that the victim was raped, and although they can identify the ${ }^{10}$ Originally aired 20/04/04. 
rapist as left handed from the pattern of the bruise marks, the offender has cut the victim's nails and washed the body to leave no DNA behind. Within the surveillance narrative however, the body always has a story to tell. From the stomach contents of the victim, investigators produce a time-line and from a piece of the condom, they match the brand. From the precautions taken to conceal any evidence, the investigators assume that the killer is an expert.

The next step for the detectives is to identify the victim, and once they do so, they realize she is a graduate student researching ex-convicts. They question her advisor, the ex-convict that she was interviewing, and her research partner, who claims that the victim was at odds with her advisor and had requested that he be replaced. The only human witness providing a time-line is a delivery man who claims that the ex-convict was at the victim's home when he delivered food. The detectives then suspect the ex-convict of the crime. When they find a book on the suspect that was written by the victim's advisor, they realize the advisor is also an ex-convict. The case then takes a different turn; since the advisor was sent to prison years before by Captain Cragen, Cragen now gets involved in the case with a personal interest in locking the advisor back up.

Despite his not-guilty plea, the detectives find the same brand of condom at the advisor's home, along with footage from a red-light camera that captured his Lexus parked outside the victim's house the night of her death. He clearly has a sexual relationship with the victim. The evidence and the camera footage of his car trumps the advisor/ex-convict's word, and he is arrested and sent to jail. However, by further analyzing the camera shot and zooming in, it turns out that the car parked outside the victim's house was the exact model as the advisor's, but with a different licence plate 
number. The detectives then search the plate number on a database, realizing it is a rental car. They track the car to the victim's research partner who had used the advisor's expertise and experience to frame him because he, too, was in love with the victim.

Surveillance technology plays an interesting role in this episode as it is initially given credence over the suspect's testimony, but the detectives quickly realize the way in which it is used by those with knowledge of forensics and surveillance in order to frame the innocent. However, again in the conclusion, authorities use the technology for the social good. Clearly the democratization of surveillance and forensic knowledge are risky. Fostering the notion that surveillance and forensic evidence supplements the lack of seeing and matching, as both the camera and the databases used imply, the detectives demonstrate therefore that the technology itself is neutral.

\section{Surveillance is Everywhere: Its Demand and Critique}

Surveillance technology includes mainstream technologies such as CCTV cameras, wire-taps, subway passes, and loyalty cards, but also the more invasive forms that promise medical care, or convenience like RFID chips and GPS locators, or heat imagers that can locate illegal activity or find bodies otherwise invisible to the naked eye. Biometric technology and database software have helped identify and segment individuals as scholars have demonstrated. Yet these technologies are simultaneously represented as necessary when it comes to today's risk society and the security issues we face in a post $9 / 11$ world. Their accessibility to citizens through camera phones, spy-ware and tracking devices have helped break the top-down notions of surveillance, making it seem potentially democratic and non-threatening (Poster 1990). Conversely, as the 
narrative in the Law \& Order franchise exhibits the horizontal expansion of surveillance, it also criticizes the open access to information through the use of the technology by just anyone. This critique rests, not on the idea that technology is dangerous, but on the notion that the intent to use it to infringe on others' privacy, or to target individuals, is an ongoing problem. This is transparent in not only the detectives' and district attorneys' dialogue but in how they approach the use of surveillance technology. They see the technology as an extension of the witness. They need surveillance technology to help them solve cases: to see the crime, to locate a suspect, to track phone and bank records, and to match suspects' activities and DNA. The technologized evidence they collect does not replace the witness, nor is it always given credit over the live subject's word. Instead, it offers witness testimony where there otherwise wouldn't be any or where it does not offer the full truth.

The technology used in the Law \& Order franchise helps the witness recall an event, to confirm their experience and to speak for the absent, the forgotten and the unseen. The technology enhances their experience but does not replace their agency and credibility in the courtroom. As the techno-witness's testimony may be excluded in a case, the eye-witness's is not. The subject gains the authority to testify as to what they saw or heard, namely their experience, but also, the human subject is used as an 'expert witness' when it comes to psychological analysis and forensics. The expertise of the expert witness helps interpret the testimony of the technology, demonstrating the necessary distinction between the technology and the subject. The findings of the technology are therefore framed as secondary to the subject. The witness, whether it is he 
or she who experienced the event, or the 'expert witness', who is brought in afterwards, helps transform the data spoken by technology into information and communication.

As the Law \& Order franchise continuously demonstrates, human agency is not lost as the programs address, credit and privilege eyewitnesses' testimony over technological evidence. The loss of agency and of 'self' implied by Haraway, although addressed and visible within the shows, it is not manifested as the two series try to validate human agency despite also using surveillance technology. They manage to explain their use of the technology by separating it from the work of the detectives or the witness, thus implying that although technology enhances, it does not become one with the body. In conveying this, they reclaim the subject's agency over the technology.

Referring back to Ford's notion of prosthesis, the assumed deficiency within the amputated human body that is compensated for with surveillance technology is echoed in the way in which the Law \& Order franchise employs technology as the extension of the body for the witness. As Marx's notion of alienation, which he attributes to the connection between the material thing and social relations, conveys, surveillance technology is perceived as the extension of the human lack resulting in alienation which creates mistrust between people, forcing them to turn to technology to witness what is left unsaid or unknown. This alienation is expressed in the narrative of the Law \& Order franchise, through the way in which the authorities control the proper use of technology. By frowning on its risks, which come about when it falls into the hands of just anyone, the top-down approach to the use of and access to surveillance technology results in the alienation of the many. 


\section{The changing nature of the witness}

The Law \& Order franchise clearly prefers Peters' configuration of the witness. The use of surveillance technology becomes a necessity, whether it is to witness or only to act as a prosthetic to an existing witness. In terms of the nature of the witness discussed earlier, the Law \& Order programs exemplify how witnessing is changing. Forensics and surveillance technology today allow for a change in the notion of 'subject' or 'one' to that of technology. This is why Peters' approach to the witness helps explain the discourse present around the witness in the Law \& Order franchise. Peters does not define the witness as a subject; in fact he notes that it can be a live subject, a form of action or an ambiguous form, hence the object that performs the act, is not necessarily a human body. Rather, it is a surrogate to the absent eye-witness. Surveillance and forensics come to serve as the surrogate to the absent; the lack that Peters discusses is either the truth or the lack of the capability of the human body in making sense of the information it collects. We thus rely on technology to get at that truth.

Peters' suggestion that the human subject as the witness is motivated to lie, and faces memory problems and inconsistencies, are all issues that the Law \& Order franchise addresses by depicting the human subjects as unreliable. In the Law \& Order programs, the formula that is present in each episode demonstrates that human subjects do lie, and this leads the detectives on a number of dead ends before they get at the truth. Memory problems after a rape, lying about one's alibi or covering for another, and the inconsistency in witness testimony all reaffirm the reason for which technology becomes a necessary component of discovering the truth. The human witness, however, is not rejected completely. 
As in the Law \& Order franchise, Peters demonstrates the scrutiny that a live subject faces as a witness. Law \& Order's discussion of witness intimidation as a moral and ethical issue with potentially significant effects on a case, confirm Peters' ideas and his use of Aristotle in stating that the dead body is a more worthy witness than a live one because it cannot be bribed. Law \& Order focuses on this notion, but in the end it also legitimizes the technologically enhanced human subject as the credible witness.

From the examples included above and the other episodes analyzed throughout my research, it becomes evident that the Law \& Order franchise endorses the witness function in the justice system, giving agency to the live subject over technology by demonstrating both the flaws in human nature and in technology. The programs distinguish between the body and technology through the way in which they treat the role of the witness. The boundaries between the body and technology are clearly signified, but that does not mean that the programs dismiss the usefulness and convenience of surveillance technology. They highlight how technology extends our body, helping us to see, store information and match it, providing a supplement to the limitations of the human, rather than a replacement.

Both franchises approach the human figure as incomplete, incapable of dealing with the amount of data that is gathered in current society, and requiring technology in order to make sense of it in the enactment of effective witnessing. In the Law \& Order franchise, the narrative offers prosthesis as a measure of being 'fixed'. The idea is not that technology should replace the human incapacity, but that it is an extension to solve those incapacities. The Law \& Order franchise's discourse of prosthetics and its narrative 
of surveillance is ultimately humanist, demonstrating the flaws, and the moral issues that surveillance can produce, but ultimately always recentering the human. 


\section{Chapter 4}

\section{Seeking Objectivity: \\ The Posthuman Replacement of Man with Machine}

Why, if the computer has moved in, should there be a human witness? What might such an onlooker reveal about the apparent apocalypse? If technology has truly sped us outside and beyond the space of humanism, why is Man still at our side? If Man is present at his own funeral, how can he possibly be dead?

(Badmington 2003,13)

In Neil Badmington's (2003) work on posthumanism, he refers to the cover of the 1983 Time magazine 'Man of the Year' issue where, for the first time, instead of a person, the computer graced the cover. He viewed this as the apocalypse; the end of the human and the confirmation of an era in which the machine had transcended man. He was surprised both at the cover and at the subsequent letters to the editor which both praised and criticized the magazine's choice. Upon further analysis, Badmington realized that the figure of the man was in fact on the cover, shifted to the edge of the frame, but still hanging on in the margins. His analysis hence does not see posthumanism as a complete rupture in humanity, but as a transgression in which both machine and human exist simultaneously, with the former dominating the latter. His analysis differs from that of Hans Moravec's (1988) linear trajectory from the regime of the human to the posthuman, or Raymond Kurzweil's (1990) approach to intelligent machines as the next evolutionary development. Although the arguably overzealous literature in the emergent field of posthumanism assumes the obsolescence of the body, Badmington proposes that to understand posthumanism, we must take humanism into account and that, by doing so, we carry on our history in "the sedimented and enculturated instantiations of our pasts that we call our bodies" (Hayles 2003,137). 
In the CSI franchise, the role of the human subject as witness and its relationship with surveillance technology convey the same message. The human, as an embodied being, is still present within the frame, required to gather data and share experiences, but as each program's dialogue and plotline unfold, the franchise places the technology at centre stage, granting it agency. It offers objectivity and intelligence that allow it to provide a superior truth to that of the human. The 'human' may not disappear entirely, but rather than appearing as central, with technological extensions, as he is portrayed in Law \& Order, he is pushed to the side, subordinate, replaced by the neutral superiority of the technology.

The CSI franchise positions itself in a dichotomy between subjectivity and objectivity, often conveying this distinction by pitting "the witness against the evidence", or embodied identity against the digital data double. The latter element of each dualism is seen as the source of truth, while the former is seen as a web of stories, as human-centred, and as necessarily subjective. The CSI franchise mobilizes these distinctions and discredits the witness and the authorities, affirming technology, properly used as the only site of truth production.

The human subject as the witness is discredited through the concepts of human flaws, trauma, self-interest, fear and humanity itself. The authorities are discredited by being subject to ambition, greed, and comuption which therefore prevents them from producing the truth. Technology not only replaces the witness, but, it could be argued, it in fact emerges as a character within the shows. By focusing on the devices used, adding music, lights, and split screens, and by the continual emphasis placed on and celebration 
of the devices and forensic techniques, technology is able to take the lead while relegating the human subjects to the background.

With its focus on the technological replacement of man by machine, posthumanist literature can be productively employed to understand the replacement discourse within the CSI franchise. The literature highlights the posthuman as a hypothetical future being whose capacities exceed those of present humans and who is no longer unambiguously human by our current standards. The posthuman was once a human and thus a prerequisite for a posthuman is a transhuman, the point at which the human being surpasses his or her own limitations but is still recognizable as a human person. Posthumans can be a symbiosis of human and artificial intelligence, or uploaded consciousnesses, or the result of many smaller technological augmentations performed on a biological human (Bostrom 2005, 205). Some of the ideas within posthumanist literature tend to convey that in the posthuman era, machines will be gods and that complex machines are an emergent life form. As well, consciousness is not exclusively restricted to the brain and the function of an organism. Posthumanism views the human body as having no boundaries, suggesting that there is nothing external to a human, as the extent of a human cannot be fixed (Pepperelli 1995, 3).

Critical posthumanism does not advocate this full transcendence, but rather explains posthumanism by offering a re-writing of the concept of humanism Humanism, as a perspective, began in the Enlightenment and claims humans as autonomous, rational, and capable of free will by their nature. These characteristics are now being challenged and deconstructed in posthumanism (Simon 2003, 4). The posthuman recognizes 
imperfectability and disunity within the self and is an alternative to the fixed, authentic, and universal conceptions of humanism (Simon 2003, 4). Posthuman practice is the ability to fluidly change perspectives and manifest oneself through different identities. The posthuman ontology is indebted to postmodern philosophy, biotechnology and evolutionary biology, hence it is a field in motion. The posthuman is not necessarily a human in the first place, but is rather an embodied medium through which critical consciousness is manifested.

The posthuman is an extension of the concept of the cyborg that Haraway's (1991) work emphasizes, but also looks beyond the fusion of machine and man. One of the most profound works in the posthuman literature is N. Katherine Hayles' How We Became Posthuman (1999), in which she attempts to explain the concept by looking at its most extreme example: Moravec's (1988) theory of rebooting a computer with human consciousness. She suggests that the prospect of the posthuman simultaneously evokes both terror and pleasure in us (Hayles 1999, 283). She argues the human being is an embodied being and its complexity means that human awareness unfolds differently from that of the embodied cybernetic machine (Hayles 1999, 284). Hayles thus perceives Moravec's notions as biologically and politically unviable as she sees the body as the net result of thousands of years of evolutionary history. She argues that Moravec's position is ahistorical.

Hayles summarizes posthumanism by defining its four central points. First, that the posthumanist view privileges informational pattern over material instantiation, in that embodiment as a biological substrate is seen as an accident of history. Second, the 
posthuman view considers consciousness as central to human identity. Third, it understands the body as the original prosthesis that we learn to manipulate; extending or replacing the body with other prostheses becomes a continuation of a process that began before birth. Finally and most importantly, Hayles notes that by these and other means, the posthuman configures the human being so that it can be articulated with intelligent machines (Hayles, 1999, 2-3). In other words, the posthuman is a being that relies on situated objectivity and on the creation of meaning through play between construction of the informational pattern and reduction to the randomness of on/off switches that are the digital binary coding for the machine.

Founded on a view of information that conceptualizes it as distinct from the material substrate in which it is embedded, Hayles (2003) identifies a dichotomy between materiality and information which is played out as the belief that information captures all that is essential about the organism. Hayles notes that the difference between biology and computer sciences is that unlike in artificial life, where the materiality of the organism literally translates into information patterns, the biological sciences do not lose sight of the carbon-based materiality in which the information is expressed. Information is hence seen as "the handle through which the materiality of the organism can be manipulated and transformed" (Hayles, 135). As critical posthumanism equates a change in the code with a change in the body, Eugene Thacker (2003) claims that materiality is seen as the site at which information patterns exert control over form and function. Thacker envisions his work on tissue engineering as what he terms 'biomedia', implying that information tends to produce the body purified of errors. In such purification, the body is 
not only regenerated but is redesigned by its informating through informational codes. The term 'biomedia' captures the tension between the body's materiality and the idea that materiality is essentially a substrate for information. In other words, biomedia sees flesh as the material carrier for the information it expresses (Hayles 2003, 137). This purification further explains the distinction of the body as a material source for technology that CSI espouses.

Reinforcing the CSI franchise's absolute reliance on forensics, Thacker takes Hayle's work on the history and discourses of cybernetics into the bioinformatics practice, showing that materialization is at the heart of understanding bodies in terms of information (Simon 2003, 6). What Thacker means, however, is not that bioinformatics represent a repression or denial of the body, but rather that the relationship between the biological body and information technology is such that the body may be approached through the lens of information (Simon 2003, 6).

Demonstrating the difficulty of distinguishing the embodied with the disembodied, Teresa Heffernan (2003) observes that the more the essence of the human is sought, the more the lines between man and machine are blurred (Heffernan, 118). Annette Burfoot's (2003) work further emphasizes the dichotomy of discourse versus materiality as she argues that the discursive construction of the body is folded back into its materiality, insisting that lived experience through the body must be seen as interrelated with discourse (Hayles 2003, 135).

Posthumanist literature offers an understanding of the relationship between body and technology beyond the idea of prosthetic enhancement. The notion of biomedia and 
bioinformatics blur the boundaries between machine and man while also granting agency to the former. The literature identifies the body as the source of information, emphasizing information patterns over materiality. The importance placed on technology affects the way in which the human subject is approached in relation to the machine. The literature thus allows for an understanding of the replacement discourse that the CSI franchise insinuates through its narratives.

\section{CSI: Post-Humanist Replacement}

Posthumanism approaches the human witness as that which is transcended by technology. Posthumanism achieves this by challenging the value of the human subject and affirming technology, which is also what CSI manages to do through a discourse of replacement. The notion of replacement and the distinction made between objectivity and subjectivity are ongoing themes in all three of the CSI programs, as the franchise builds on the action and intrigue of detective work by focusing on the collection of evidence, and the scientific work that helps crack the cases. Drawing upon the critical posthumanist literature, this chapter will look at the concept of the replacement of human by machine. It is not just the emphasis on the scientists' work that legitimizes technology, but in the portrayal of technology as the only means of getting at the truth, the replacement discourse authorizes technology over the human subject. This plays out particularly in relation to the figure of the witness.

Using the latest and yet-to be invented surveillance technology, the three series employ the widespread use of CCTV cameras, camera phones, recorders, GPS locators, 
biometric scans, forensic science, blue lightening, and heat imagers (among others). They turn to the everyday usage of loyalty cards, subway passes, university cards, phone and credit card records, as well as to the more advanced use of sound editing, facial software, databases, Internet Protocol address tracking, and residue testing. These devices allow the investigators to see and match data, track the crime, locate the offender, and solve the cases. However, these technologies are not only adopted to extend the investigators' work, but are employed to reveal the truth, to discredit any witnesses, and to ultimately replace the witness by providing, not merely testimony, but evidence.

The issue of the 'CSI effect', mentioned in the Introduction, stems from the dialogue and moral stance that the CSI programs adopt. Research has shown that the programs' foolproof dependence on surveillance devices and forensics, as well as its popularity on television, has altered the way in which people approach crime cases. This change is exemplified by Tom Tyler's (2006) explanation of how jurors today demand more surveillance and forensic evidence from a trial in order to convict criminals. What the programs and the 'CSI effect' exemplify is the change in the nature of the human subject as the witness, and people's understanding and acceptance of surveillance devices.

\section{The Discrediting of Man}

CSI investigators rely far less than their Law \& Order counterparts on witness testimony. In fact, much work within the show is done to disparage the witness. In CSI: NY's episode 'Tri-Borough', when Det. Taylor questions "Did anyone see anything?", 
Detective Don Flack responds "When does anyone see anything?" (CSI: NY, "TriBorough' 1-11). ${ }^{1}$ Similarly, in expressing the likelihood that there are no eyewitnesses to the crime, or that people may not admit to witnessing it, Stokes states in CSI: "No one saw; someone is lying" (CSI, 'Coming of Rage' 4-10). ${ }^{2}$ The show also recognizes discrepancies between witnesses. In 'Wannabe' (CSI: Miami, 2-18) ${ }^{3}$, when Cane is asked if there are any witnesses, he responds, "Yeah, four eyewitnesses and four different stories". The investigators then dismiss the human subjects as witnesses, and by collecting physical evidence with and through technology, they privilege the technowitness. The testimony of the human is a story, that of technology is truth.

The definition of the witness as one who is endowed with the power to establish facts guarantees the clarity of objects where their subjectivity is their objectivity (Haraway 1997, 4). In the CSI programs, however, this objectivity is given to technology due to its neutrality, its speed, its efficiency and its detachment from the flaws of human behaviour. When there is a witness to a crime, as is the case in 'Witness to Murder' in CSI: Miami (2-12) ${ }^{4}$, his testimony regarding his memory of the events is questioned due to his mental state. In the episode, Eugene witnesses the murder of a man in an underground parking garage; however, since Eugene has a mental disorder that places him at the mental age of seven, Horatio Cane expresses his doubts about his capacity to be a witness: "No jury will find Eugene competent". When Det. Frank Tripp responds

\footnotetext{
${ }^{3}$ Originally aired $1 / 5 / 2005$.

${ }^{2}$ Originally aired 13/12/03.

${ }^{3}$ Originally aired $12 / 01 / 04$.

${ }^{4}$ Originally aired $01 / 12 / 04$.
} 
that "A witness is a witness", Cane replies, "Let's stick to the evidence". Cane is thus clearly distinguishing between the witness and the evidence. For him, they are unrelated.

The reputation of the human subject as witness is tied to his or her credibility, and when that credibility is put on trial, any flaws can discredit the witness and weaken the case. In CSI: NY's 'Supply and Demand' $(1-20)^{5}$, a young woman's college roommate is killed and the CSI crew believe she was the actual target for 'the hit'. At the same time, two other college students die due to overdoses and the investigators believe that the cases are linked. The detectives access the young woman's university card to track her connection to the other victims and realize that she is responsible for selling drugs to them. As they race against time to save the last person who bought drugs, they concurrently find a suspect for the initial murder of the roommate, who admits that the girl stole his drugs and things got out of hand when he attempted to get his products back. They track the young woman and find her at her parents' home. When her lawyer is told that she is charged with selling drugs and that there is a witness who will testify that she sold her heroin, the lawyer discredits the witness stating, "You are expecting people to believe the word of a druggy?" Burn responds, "That is why evidence collecting is important, because people lie". Despite having a witness, the investigators undervalue the worth of the human subject by reducing it to its flaws, a web of lies, and recognize instead the value of technologized evidence.

Even where the witness is also the victim of the crime, the CSI franchise questions their testimony because of the way in which trauma can affect people's

\footnotetext{
${ }^{5}$ Originally aired 27/04/05.
} 
experiences. In CSI: Miami 'The Best Defence' $(2-5)^{6}$, when the team arrives at a shoot out, the victim who initially called the police is rushed to the hospital, but not before Cane questions him about what happened. When the victim says that he was shot once, despite the clear presence of two bullet wounds which confirm that the victim was shot twice, Cane rejects the victim's statement claiming that, "Trauma misguides us, but evidence will tell us the truth". He then, of course, turns to forensics. Later in the episode, as the case unfolds, the truth is revealed that the victim had set up the shoot out himself and was shot by his own lawyer. The fact that the victim lied further confirms Cane's understanding of the human subject's unreliability, and the reason for which the CSI team embraces the use of technology to unearth the truth. This is also the case in 'Invasion' (CSI: Miami $2-15)^{7}$, when a family's home is invaded and the father is killed. When the wife is taken to the hospital for a checkup, Cane encourages her to get a rape test but she declines stating that she was not raped. Despite her assertion, Cane again states that, "Traumatic events can affect memory". Although in this instance the victim was correct, the insinuation that she would not remember correctly, despite being both a victim and a witness to her own violation, further reinforces the mistrust of people and the replacement of their testimony with the information that forensics and surveillance technology can attain.

Distrust of the witness in the CSI franchise signifies its unforgiving perception of the human subject, expressing the witness as a problem. In the Law \& Order franchise, however, although the witness is portrayed as flawed and weak, he or she is nonetheless

\footnotetext{
${ }^{6}$ Originally aired $20 / 10 / 03$.

${ }^{7}$ Originally aired 23/01/04.
} 
redeemed through their potential to help solve the case, signifying the witness as still a reliable source of truth. Even so, as with Law \& Order, witness intimidation is a problem, and the $C S I$ franchise demonstrates this in CSI: New York 'The fall' (1-17) ${ }^{8}$, when a gang robbery leaves a store clerk dead. The detectives try to get information from the several witnesses who saw the young perpetrators run off, however no one is willing to talk. Det. Taylor quips, "Unfortunately for gangs, they cannot intimidate evidence". As the case unfolds, it is the surveillance camera in the store that identifies the three boys who committed the robbery. On the video, one of the boys is seen entering the store with a pop can, and so the investigators look for the can to collect and test his DNA. Again distinguishing the witness as separate from the material information he/she provides, the case is solved through surveillance and forensics, all witnesses remaining silent. This reinforces the importance of both surveillance technology and the biological material which the individual leaves behind as the only means by which to get at the truth, when the human subject is too intimidated to speak for the Other.

The ongoing practice of discrediting the human subject is justified not only through the flaws of criminals, the traumas of victims, or the credibility of drug dealers and those suffering from mental disorders, as mentioned above, but also in the representation of the detectives. Fostering the notion that authorities (as humans) are also flawed, the CSI franchise demonstrates that the human subject cannot see, track and pick up on every detail, even if they are detectives themselves. They, too, need technology to

\footnotetext{
${ }^{8}$ Originally aired $3 / 2 / 2005$.
} 


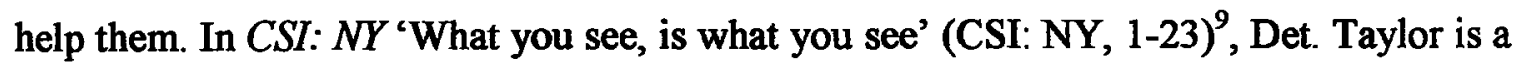
witness to a crime at his local diner. When the CSI team arrives, after the suspect has left the scene, they ask Det. Taylor 'If there was anything found?' He responds, "Nothing different from what I witnessed". At the end of the episode, however, with the help of the evidence collected physically and from surveillance technology, the case is solved, calling Det. Taylor's own witnessing into question. He responds without anger: "That is why you don't rely on eyewitness testimony, because I saw what I saw but the evidence knows what was really going on". The witness and evidence are two different things; while one is subjective, the other is objective. In other words, Det. Taylor replaces his own experience and the validity of what he saw by crediting the evidence, fostering the idea that what the human subject sees is just that but what technology allows the investigators to make sense of is evidence, the visual record of what actually took place. Only technology offers truth. The technology reproduces the human activities of seeing, but without human flaws which put the witness at risk of being discredited. Referring back to Badmington's initial reaction to the machine, Det. Taylor pushes himself to the background while instead shining the light on technology.

The flaws of authority figures are also addressed in CSI: $N Y$ 'The fall' (1-17), when the local police officer, outside the CSI team, omits the store clerk's witness testimony upon realizing that his own son is guilty of the crime. When Detective Don Flack questions the police officer, he refuses to admit to hiding evidence, but Det. Taylor decides to turn to the body for the truth: "Lets go back to the body". The episode deals

\footnotetext{
${ }^{9}$ Originally aired $18 / 5 / 2005$.
} 
with the moral dilemma that the officer faces as a father, the initiation of boys within gangs, and the intimidation of the public by gangs. In the end, the officer loses his badge for covering up his son's crime. While sympathetic to human weakness, technology is legitimated as the only way to be certain about the truth and to, therefore, do justice.

\section{The Crediting of the Machine}

The first step in the replacement discourse is to discredit the human subject, thus creating a gap in agency which is then filled by technology. This discourse reasserts Staples' (1997) notion that modern disciplinary technologies are founded on the desire to derive knowledge from the body. Staples notes that technology tends to reduce the need to trust the word of offenders or for suspects to speak the truth, but rather relies on their objectified bodies to provide us with essential information, and in turn help to further mobilize surveillance. In CSI, tape recorders, surveillance cameras, fingerprints, DNA and GPS locators are all introduced as reliable witnesses, achieving the second step in the replacement discourse, the thorough crediting of the machine.

In CSI: $N Y$ 'On the Job' $(1-21)^{10}$, when the team finds a sound recorder that taped the shooting, their response is, "We may have found our only reliable witness". They instantly dismiss the other witnesses, and turn to the recording to tell them unequivocally what happened. The recording provides information via sound editing analysis, a process of isolating certain noises and heightening others. This process involves more than simple technology; it requires the expertise of the sound editors. The investigators, however,

\footnotetext{
${ }^{10}$ Originally aired $5 / 4 / 05$.
} 
credit the actual recording as the witness, deemphasizing the skills required to transmit the data into information. The human technicians move to the background so the technology itself can shine, again.

This replacement of the live subject with technology as the provider of evidence is demonstrated and legitimized throughout. In 'Witness to Murder' (CSI: Miami, 2$12)^{11}$, the second case involves the murder of a young girl who was pushed down the stairs. The team initially suspects the father, but learns that he was having an affair with his wife's sister. His daughter discovered the affair and confronted her aunt. In the ensuing scuffle, as the girl struggled to keep her balance, she scratched the suspect, trapping skin cells under her nails which both place her aunt at the scene of the crime and mark her as the one who pushed the victim. In the conclusion of the episode when the team arrests the aunt, she states, "He promised he wouldn't tell" referring to the girl's dad. Duquesne responds, "He didn't: DNA did". People will lie to protect others, therefore the human subject cannot be guaranteed to always speak the truth. DNA matching technology, however, speaks uncontestable truth.

The emphasis on technologized evidence as a means to produce truth is again conveyed when Duquesne's father prosecutes a case in which the suspect has entered a guilty plea, despite the fact that the prosecutor believes her to be innocent. Duquesne's father turns to her for advice. Her response is simple: "What does the evidence say?" Her father responds, "There is no evidence" and Duquesne returns with, "There is always evidence". Again evidence and human testimony are perceived to be unrelated, as

${ }^{11}$ Originally aired 12/01/04. 
evidence, unlike witnesses, is always present and always true. In all three series of the franchise, there is always a potential absence of witnesses, but never an absence of evidence. Getting to the story may be impossible, but objectivity and truth will inevitably shine through with the evidence necessary to reveal the truth: that which is produced through the use of surveillance technology and forensic science. Cane summarizes this notion best, "We will not rely on an eye-witness, the only thing that matters is the evidence" (CSI: Miami, 'Blood Brothers' 2-1). ${ }^{12}$

There is a significant difference between the CSI and the Law \& Order franchises, in that their ontological premises set them apart. As the crime drama genre seeks the truth, its understanding of truth becomes fundamental to its approach of solving the cases, and as a result, in how it sees the role of the witness. In Law \& Order, the truth is assembled together through the various stories that the detectives collect, hence truth is constructed. The objective is to question witnesses, those involved, and to investigate motives, in order to produce the truth. In CSI, however, truth is revealed; the understanding is that the truth is not produced but exists somewhere 'out there', and technology allows for it to be exposed. Hence Law \& Order views the witness as relevant in the construction of truth, whereas in CSI, the witness and his/her flaws only obscure the epistemologically pure truth that the teams attempt to attain by employing technology to collect evidence. The CSI understanding is that the neutrality of technology will inevitably allow for the pre-existing truth to be reached.

${ }^{12}$ Originally aired 22/09/03. 


\section{The Subject Disembodied and Body as Information}

Unlike in Law \& Order, where the DNA is minimized as just another investigative tool, the CSI franchise holds evidence, particularly DNA, as the absolute technology. The substitution of technology for the body depicts the body as a source of information, as it was in Low \& Order, but CSI goes further to render the actual body irrelevant once it is disembodied. Placing emphasis on traces of the body rather than the body itself, the CSI franchise takes a post-humanist approach to viewing the material of the body, rather than the embodied identity, as the source of information. The body is seen as litter for CSI; thus one cannot talk about the human subject in the franchise without discussing the way in which it treats the body. Following Hayles' separation of the body from the human subject, CSI renders the body into codes and bits of flesh by deromanticizing the concept of the body and by conveying it as meat to be discarded.

Such an approach obscures the invasive nature of biometric technology, as the scanning of the iris, hand, facial geometry etc., appears harmless. However, as Van der Ploeg (2002) demonstrates, biometric technology is dangerous as it blurs the internal and external boundaries of the body and makes public information about the person beyond that which they would otherwise be required to disclose. Thus the failure to understand the invasiveness of biometrics and the replacement of the embodied identity with the digital data, requires a discussion of bodily integrity (Van der Ploeg, 60).

The increase in the generation, collection and processing of the bodily data is also addressed by Lyon (2001) in terms of its potential to affect the various domains of society and spheres of activity from work, to health care, to law enforcement and even to 
the common activities of consumption, travel and leisure. To Van der Ploeg, bodily integrity applies to the body itself, whereas informational privacy is presumed to cover all representations of it. Van der Ploeg uses the example of piercing the skin with a needle to draw blood as a violation of the body's integrity, despite its common justification. Although not all processes are as clear cut, and examples like the X-ray photograph are harder to categorize, they are invasive as the picture tends to constitute a representation of the inside of the body (Van der Ploeg 2002, 68). The difficulty in categorizing and setting boundaries between the internal and external, relate to the problem of the immature state of legal regulations surrounding the use of the body as information, which is enabled by advances in technology, despite the fact that the 'rights' of the body are not well established.

The relationship between bodily matter and bodily information cannot be understood as the boundary between the thing itself and representation of it. Van der Ploeg notes that there is no clear point where bodily matter first becomes information. However, she states that the use of body data involves the data or the information and not the body, or the embodied person themselves, thus denying the constitutive and enduring relation between the data and the identity as the embodied person. In other words, if the stored information collected about a citizen's behaviour is inseparable from the person, then the inclusion of body data in a digital biography is similarly inseparable from the embodied identity (Van der Ploeg 2002, 72). In the CSI franchise, body integrity is overlooked as the narrative and the dialogues are not critical of posthumanism but rather embrace its notions. 
As Dubbeld's work would also suggest, surveillance technology that witnesses a crime or matches fingerprints across a database can overcome the disappearance of the physical body as the digital information abstracted from the body can lead to the conviction of the embodied self (Dubbeld 2003). CSI: Miami demonstrates the fact that the physical body becomes scrutinized through political and legal approaches that view it as material and genetic. In 'Blood Brothers' $(2-01)^{\mathrm{i} 3}$ when the offender, Clavo Cruise, spits on Cane, the detective thanks him as he takes the DNA to be tested against the evidence collected at the scene of the crime, which in turn ends up proving Clavo's guilt. In 'Wannabe' (CSI: Miami, 2-18), it is the hand-print on the dead body and the bruising imprint of the hand used to apply pressure and choke the victim that helps the team find the killer, through measurements of the dimensions of the hand-print stored across databases.

The return to the dead body, over the human subject, reaffirms the lack of validity of the human witness, as is conveyed in both CSI: NY's 'Supply and Demand' $(1-20)^{14}$, and CSI: Miami 's 'Witness to Murder' (2-12). ${ }^{15}$ In the latter, the offender is arrested, not due to witness testimony or the surveillance technology which witnessed the crime, but to the DNA left under the victim's nails, and the bruises on her body that insinuate she was pushed. In the former, when the suspect is captured in a chase, he states that he knows his rights and will not give his DNA, to which Det. Taylor states, "We have rights to everything on, or outside your body, and that's enough". Their approach to the body as

\footnotetext{
${ }^{13}$ Originally aired 22/09/03.

${ }^{14}$ Originally aired 27/04/05.

${ }^{15}$ Originally aired 12/01/04.
} 
material and the site of information provides a posthuman understanding that demonstrates the extent to which the body can be pinpointed as the source of truth.

Although Van der Ploeg, Dubbeld and critical posthumanist scholars explain the role of the body in detail, they do not address the observer. Forensics and surveillance devices transform the physical body into digital codes, as symbolic forms that are entered and stored in a database, accessible through specific software. Important to recognize is the fact that the body is disembodied without direct and visible confrontation, through a mediating gaze. In the CSI programs, that gaze is that of the crime lab and the detectives who comprise the team. They themselves are not scrutinized, nor is their use of surveillance technology seen as being invasive; however they do question the democratic use of the technology reproducing a top-down approach to surveillance. Similarly to the way in which Law \& Order frowns upon the dangers of surveillance when found in the hands of just anyone, through their discussion of $9 / 11$, hate crimes, and identity theft, the top-down control in CSI is reinforced by instilling the fear of future threats and implying that surveillance will prevent against risks to today's society.

The dialogue surrounding the neutrality and foolproof nature of technology is the foundation of the CSI franchise, as it helps demonstrate the difference between the evidence and the human subject as witness. Although initially the main characters appeared somewhat robotic, the imperfections of their human natures were slowly revealed to further contrast with the flawlessness of the technology. In 'Bloodlines' (CSI, 4-23) $)^{16}$, the most machine-like and "perfect" investigator of the franchise, Gil Grissom,

\footnotetext{
${ }^{16}$ Originally aired 20/05/04.
} 
faces the difficulty of having to deal with a discrepancy in a forensic test. He is forced to approach the possibility that the technology he employs has flaws, and can come up short in helping to solve a crime. In every episode, the role of the witness is questioned, evidence is collected and technology finally reveals the truth; however in this episode, the authority of technology over body becomes an issue for the team.

'Bloodlines' deals with a young woman who was attacked and raped but had managed to escape her assailant and run for help. When the CSI crew arrives, the victim, Nat, manages to help the investigators by providing not only a description of her attacker to the sketch artist, but also a correct identification in a line-up once the suspect is brought in. From her rape kit test results, they take the DNA that the suspect left behind to compare with Todd's DNA, in order to confirm the victim's statement.

The DNA results come back negative, but with similar alleles that indicate that the perpetrator is Todd's sibling. The team uses a family-tree database to locate his other brothers. Once tracked, they interview them to determine if they have alibis. When Willows tells Nat that Todd was not the perpetrator, the victim swears that she is confident and cannot forget the face of her attacker. Willows responds, "DNA ruled him out. You cannot always trust your eyes". This resonates with the ongoing replacement theme that all three CSI programs take on, which implies that evidence is more accurate than the human witness.

After Todd is released, Nat is found dead. The detectives cannot match the DNA from the crime site to any of Todd's siblings. When Todd is caught cleaning the trunk of his car, Captain Brass takes him in for another round of questioning. Grissom uses the 
blue light to look for scratch marks on Todd's back, but instead finds distinct skin skid marks (Blascho's lines) that pique his curiosity. He turns to his academic books, and finds the case of the 'Chimera', the half-man half-lion. There is a possibility, genetically, of two children being born as one; therefore the DNA of Todd's saliva differs from that of the DNA released from his waist down. This explains the reason for which Todd's DNA didn't match, despite Nat's testimony that he was the attacker.

Grissom discovers that Todd was an organ donor for another brother. When doctors performed the genetic testing required for that surgery, they discovered his genetic situation. Todd used the fact that he possesses two different versions of DNA to his advantage. In the end, when the team finds out the truth, Willows is disappointed that she privileged forensics over the live subject. Unhappy with the mistake, she states, "Nat was sure Todd was the killer. Maybe the evidence is wrong", implying that maybe their practice of turning to technology for the truth is not always a good measure. But Grissom responds, "You can be wrong, I can be wrong, but the evidence is the evidence". Grissom's statement reinforces the belief that technology is neutral, that even his own machine like persona is faulty, but that the data which becomes evidence through collection and testing, is the only reliable source. Upon closer reflection, what initially looks like a critique of the truth revealing capacity of the technology, is actually an affirmation of it. The problem in the case was once again found in the flaws of the human subjects who interpreted the evidence in the wrong way. It was the authorities that did not recognize the possibility of the case, that ignored the information they were being given, 
and that misinterpreted the information which the evidence provided. The technology was right all along.

\section{The Scientist}

Because technology is accorded such significant agency, a key question arises regarding the role and status of the scientist. Whereas in the Law \& Order franchise, the role of the investigator is vital to the construction of the truth, in CSI, the post-humanist discourse of replacement perceives the scientist as largely irrelevant. The frequent sequences of shots which depict the scientists working in their labs, emphasize the technological devices by zooming in, adding music and using split screens, which helps to reduce the scientist to merely a technician. Gone are the brainstorming and scientific revelations, replaced instead with routinized, absolute methodical technical forms that the team must follow. Their subordinate status is demonstrated through a focus on the collection and reporting of evidence, the absence of meetings, and the fact that the only discussion of the case centres around the results of technologized evidentiary practices, as opposed to scientific revelations or theories. For example, in CSI, Greg Sanders was promoted from a technician in the lab to an investigator, however his responsibilities did not change, only his position in relation to the team was altered. He continues to follow the very same technologized routines that he used as a technician in his investigative work. In other words, the discourse of replacement seems to suggest that anyone can do the testing, thus further degrading the role of man and shifting it to the margins. 


\section{What Happens to the Witness?}

The nature of the witness as conveyed in the CSI franchise shifts from a subject speaking for the other, to the technology that is capable of taking data, making sense of it, and in turn, communicating the experience to the investigators and scientists. The legitimacy and authority given to technology over the body renders the latter, the witness, unreliable and obsolete. As Peters' (2001) reference to Aristotle demonstrates, human subjects are subjected to scrutiny; the pressures of protection, motive and trauma, as exist in the CSI franchise, leads the teams to the dead body which is the witness. The body is no longer viewed as an embodied identity but as evidence. By displaying this, they convey the necessity for surveillance technology. They do not address the problem of the gap between the legal system and the current technology, or the suppression of surveillance technology (in court). Furthermore, because the offenders are presumed to be both guilty and convicted by the end of each episode, surveillance technology appears to inevitably guarantee absolute guilt and conviction.

In Law \& Order, convictions and the justice system are not clear cut. Guilty people may walk, plea bargains may be given to the guilty and the suppression of evidence is normalized. This reality helps convey both the moral and ethical issues that the characters face and the flaws of the justice system. These very same facts are completely absent in the CSI franchise's reliance on technology to reveal the truth. While CSI celebrates the victory of science over man in putting the guilty behind bars, in Law \& Order, there is often a lack of closure. For the latter franchise, a case is just another case, 
as each episode ends with the detectives returning to their desks and with the D.A.s going home, only to face these obstacles again the next day.

Applying Thacker's concept of biomedia in understanding the body as a carrier for the information it expresses, the breaking down of the physical and the material allows for bioinformatic practices that see the relationship between the biological body and information technology as inseparable while viewing digital data as separate from embodied identity. This understanding overlooks the invasiveness of data collection and leads to the misconception that the gathering and storing of digital data is less intrusive than placing a camera in the privacy of one's home. The body is seen as a series of components, and thus as irreducible matter without bodily integrity. The danger of this understanding is not recognizing the infringing nature of invasive technologies, and viewing the embodied identity, once scanned, as irrelevant.

As both crime dramas have the same goals, solving the crime, convicting suspects and bringing justice, their difference lies in the way in which they approach the body, technology, the truth and the witness. Both Law \& Order and CSI franchises demonstrate the problems of the post panoptic, and the post $9 / 11$ society in terms of the risks of the democratic use of surveillance. They are also similar in the way in which they tackle the issue of who should control surveillance and the need for technology. However, one uses technology to extend, the other to replace. One sees the human witness as problematic but necessary, while the other finds it problematic and irrelevant, replacing it altogether with evidence. 
Referring back to the opening quote by Badmington, the idea of replacement may assume the transcendence of man by machine, but as both the image of man on the cover of Time magazine, and the posthumanist literature demonstrate, as technology advances, the machine gains centre stage and legitimacy while the human subject is shifted to the side. However, the overzealous posthumanist discourse of the replacement of man with machine completely ignores the history behind the evolutionary changes of human behaviour and further assumes a simplistic, linear transgression. As the CSI team drives the plotline and is necessary for the crime drama to unfold, the role of the human proves its necessary albeit limited existence. However, in the presence of technology, the human is still pushed aside, replaced in the production of truth by the techno-witness. The duality between man and machine in the CSI programs is hence best signified as the replacement of subjectivity with that of objectivity, of witness with evidence, of stories with truth. Favouring the latter half of each binary as the legitimate measure and discrediting the former, all in a context of surveillance society in a post $9 / 11$ world, the franchise embraces technology as the site of truth production. 


\section{Chapter 5}

\section{Understanding the Witness in the Information Age}

There's a war out there, old friend. A world war. And it's not about who's got the most bullets. It's about who controls the information. What we see and hear, how we work, what we think...its about the information! (Cosmo in Sneakers, Robinson 1992)

Theorists like Ulrich Beck (1992), Manuel Castells (1996), and Anthony Giddens (2000), tend to argue that since the $1970 \mathrm{~s}$, there has been a global scale transformation from the industrial society to an information society. As steam power was the technology behind the industrial society, information technology is the catalyst for the changes in work organization, societal structure, politics and law enforcement in the late $20^{\text {th }}$ and early $21^{\text {st }}$ century. The information age includes the prominent and visible fixture of surveillance technology that enables the collection of information and promises security and convenience through the reduction of risk. The post-9/11 world has seen an overnight increase in demand for surveillance devices and the post-panoptic approach to today's technology enables the embrace of a mode of surveillance markedly different from the top-down model of the panoptic and its goal of creating docile bodies and lack of resistance.

Suggesting that surveillance technology is spreading horizontally, enabling the many to watch the few, today's technology has been adopted in various landscapes from the convenience of 'swipe and go' cards to the scanning and fingerprinting of passengers at airports. The advancement is participatory as people actively sign up for loyalty cards, use subway passes, or allow the insertion of RFID chips to track medical records. From 
CCTV cameras on street corners, to the surveillance cameras in stores, which provide security, convenience and access, information is collected.

Further visible signs of our surveillance society are evident in people's use of camera phones to capture controversial footage, in their indulgence in Reality TV, in their rampant use of networks like Facebook and MySpace, in the practices of file sharing or hacking, and in people's resistance to surveillance through sousveillance technologies (Mann et al. 2003). Haggerty and Ericson's (2000) surveillant assemblage and Mathieson's (1997) idea of the synopticon have transformed the way in which surveillance is conveyed, thus giving it the neutral, user-friendly appearance of an open system for all. Laws have been passed allowing increased access to tap phones, to track, even without suspicion, credit card records, and to access people's library records. As society changes to increasingly collect information for consumer and security measures, critiques of surveillance and its privacy infringing nature are also being discussed. However, despite the notion that resistance is possible by some (Ball (2006); Haggerty (2006); Lyon (2006)), many are not aware that data is being collected (Calhoun, 1992), or the reason for which it is collected, particularly in terms of the criteria employed to discriminate (Gandy 1993, 2006). Issues such as identity theft, child pornography, spy cameras and the sale of personal information by large corporations are brought to light by critics who demonstrate the dangers of surveillance technology and the potentially unethical use of such devices. Yet, despite the fears around its use and its normalization, surveillance is also being demanded to help remedy these very same issues, hence its necessity is simultaneously confirmed and security is promised through its use. 
Turning to popular culture, from the early 1990 s and more prominently from 2000 till present day, crime action dramas have featured prominently on prime-time television, from LA Law and NYPD Blue, to NCIS, Criminal Minds, 24, Crossing Jordan, Numbers, and Bones. The most prominent of these shows, however, are the top rated Law \& Order and CSI. The two franchises have instigated scholarly discussion over the representation of minorities, the role of scientific technology, and the justice system, while also generating phenomena such as the 'CSI effect'. Their popularity extends beyond the entertainment medium to reflect increasing enrolment in Criminology programs across the United States. The two franchises have become a driving force in popular culture, and by tackling post 9/11 American society, the ubiquity of technology, and by alluding to current news and entertainment stories, both claim cultural significance by situating themselves within the societal context of our time. In today's surveillance society, they deal with the gathering of information through their surveillance narratives.

By providing a brief summary of the arguments presented throughout this thesis, and by referring to surveillance, prosthesis and posthumanist replacement, I will attempt to put the Law \& Order and CSI franchises in dialogue with each other. Pointing out their similarities and differences, and their understanding of the relationship between the body and technology, the way in which the use of the devices is reaffirmed in the detective's work, and the way in which the truth is approached, illustrates the change in the nature of the witness. The normalization and celebration of surveillance technologies in relation to the human subject may go some way to explaining the generally favourable approach of the public to surveillance technology. 


\section{Prosthesis versus Replacement}

Chapters Three and Four have employed the two popular TV franchises to examine the relationship between the body and technology through their models of the witness. While the two offer different perspectives, they reaffirm the changes in the nature of the witness through the way in which each franchise's investigators approach technology. In Chapter Three, the discourse of prosthesis explains the extension of technology to enhance the witness. Reclaiming the role of the human subject, the technology attempts to remedy the flaws and shortcomings of humans while still granting them agency. The Law \& Order franchise further distinguishes the technology from the human, by assuming the body is an embodied entity rather than merely a material resource. This differs from the way in which the CSI franchise views these very same elements. It tends to replace the human subject as the witness with technology. Explaining technology as a neutral tool that can help 'reveal' the truth, humans are perceived as irrevocably fallible who must therefore be replaced. The human subject is thus understood to be subordinate to the technology.

The Law \& Order franchise provides a humanist discourse while the CSI franchise replaces man with machine, suggesting a posthumanist understanding of the subject. In the Law \& Order franchise, the human subject is seen as autonomous and rational, but also flawed. The franchise emphasizes the frailty of mankind, from the authorities, to the witnesses, to the criminals. The programs also exhibit the flaws in privacy laws, in the justice system, and in surveillance technologies themselves. However, they also suggest that prosthetically, the capabilities of the human subject can 
be enhanced to address its shortcomings. Surveillance cameras can enhance seeing, as can access to databases help extend the ability to match information and to track down suspects. Surveillance technology and forensics are hence appropriate in the prosthetic discourse as a controlled extension of the human.

Although the role of the witness is revealed with all its weaknesses, the dialogue within the franchise highlights these flaws while also granting agency to the eyewitness, and using surveillance technology to simply enhance what is not experienced, or remembered. The franchise's approach to finding the truth and solving crime cases is based on the notion that the truth is constructed. The faulty human subject as the witness thus becomes relevant and necessary in assembling a picture of the victim's identity, the suspect's identity, the nature of the motive, and the crime which took place. Noting that the law has yet to catch up to the capabilities of surveillance technology, and that surveillance is still in its early stages with flaws of its own, the human subject remains vital to helping solve the crimes. The traditional detective work of questioning witnesses is the driving force behind each episode. This significant approach to how truth can be reached changes how the role of the witness is perceived, and thus separates Law \& Order from its counterpart, $C S I$.

In Chapter Four, I analyze the relationship between technology and the body through posthumanist discourse in order to understand the way in which the CSI franchise legitimates technology over the human subject as witness. Adopting the notion that the truth exists in a pure form and only needs to be 'revealed', the dichotomy advocated by the franchise between subjectivity and objectivity, or that of witness versus 
evidence, suggests that humans have flaws and these weaknesses cannot be fixed. Human subjectivity is hence replaced by the objective, neutral, foolproof nature of surveillance technology and forensic science.

Placing the machine in the forefront, as truth producer, the three series within the CSI franchise echo the posthumanist literature which imbues technology with a god-like superiority over man. Privileging informational patterns over material instantiation, the CSI teams approach the body as components to be used by technology in order to communicate. As well, following a posthumanist understanding, the franchise, through its camera shots, editing, dialogue and narrative, relies on situated objectivity in creating meaning through the construction of informational patterns and by reducing randomness and subjectivity. Believing that truth is revealed, the belief in technology's neutrality is fostered by shedding light on the flaws of humans, even authorities, and by reducing the role of the scientist to mere technician. The franchise continuously distinguishes between man and machine, advancing the latter over the former.

\section{The Judicial System and Agency}

Although the CSI franchise provides an all-controlled, authoritative dialogue when it comes to surveillance technology, highlighting the plausible risks of the surveillant assemblage, it also provides a relatively uncritical view of posthumanism. It embraces technology as the transcendence of man, as a foolproof measure for revealing the truth. The human subject is continuously discredited, while the franchise overzealously advocates that 'there is always evidence' and that 'the only thing that 
matters is the evidence'. Referring to Gever's analysis, as discussed in Chapter One, the machines are depicted as the ones doing all the work. Once the genetic evidence is declared a match, the source of the information 'might as well forget hiring a lawyer'.

By eliminating the prosecution aspect of each case, the CSI franchise overlooks the problems of the justice system, the suppression of evidence, the influence of eyewitness testimony and the unfortunate instances where the guilty go free. Conversely, the Law \& Order franchise explains the importance of witness testimony by shedding light on numerous instances where judges ask the D.A.s to solve the case the 'traditional' way, or when Lieutenant van Buren, for example, tells her detectives to interview suspects rather than resort to simply tracking them down via online chat rooms (Law \& Order, 'Profiteer' 17-6). 'While Law \& Order understands that the legal system has not kept pace with the advancement of technology, this reality is completely absent in the CSI franchise. By eliminating this obstacle, the franchise reinforces the absolute agency of technology and the replacement of the witness by forensics.

Overall, both franchises work as surveillance narratives by bringing forth a didactic discourse on the ubiquity of surveillance technology, the fear of another terrorist attack, access to information, and the role that technology plays in solving crime. Aside from their direct reference to the devices, the genre, in general, requires a witness in order to access the truth and solve the cases. Hence, the way in which they approach the role of the witness is revealing of how the relationship between the body and technology are explained. The prosthesis discourse redeems the human subject as the witness, while the

\footnotetext{
${ }^{1}$ Originally aired 27/10/06.
} 
replacement discourse sees the witness as irrelevant with regards to getting at the truth. This understanding of the importance of the witness also relates back to the way in which each franchise perceives the role of the body (separate from the human subject).

As critical theories of posthumanism highlight the notion that human behaviour is an evolutionary process, they criticise the notion that the machine can entirely replace the human (Hayles 1999). Overzealous posthumanist theories suggest a change in the perception of the body from its embodied identity to its status as merely a source of information; by breaking the body into its biometric and DNA codes, it reduces the body to its material components and as such, the embodied identity loses agency. An understanding of the body in this way raises questions about bodily integrity. As the CSI teams fail to distinguish between internal and external boundaries, they therefore do not recognize the privacy infringing nature of surveillance technology.

In the Law \& Order franchise, the human-centred basis of its critical purchase on surveillance society suggests that technology only extends our abilities in order to construct the truth. The technology is just as scrutinized for its flaws as human nature is, demonstrating that neither one can be foolproof. Although surveillance technology allows the authorities to manage uncalculated risks, it is, itself, risky at best. The franchise hence mobilizes surveillance discourse without replacing the body with technology, or breaking down the body to its material components. As it views the dead body as a victim to be known, rather than as mere information to be calculated, the franchise understands the dangers of surveillance technologies and frowns upon their normalization and everyday use. 


\section{Witness and Witnessing}

As was briefly discussed in Chapters Three and Four, the difference between the way in which the two franchises approach the human subject suggests a duality between the human witness versus the techno-witness or evidence, subjectivity versus objectivity, and embodied identity versus materiality, which all combine to make up the foundation of how the discourse approaches truth. Where the Law \& Order franchise understands truth to be constructed through the piecing together of relevant information, the CSI franchise envisions it as already existing and only obscured by the subjectivity of the witness or the investigators. It must be revealed by a neutral device. The two different understandings provide for a discussion of the changing role of the witness, which raises the questions: does the human witness hence become an obstacle in revealing the truth, or does it help in its construction; does the human subject speak for the bygone, or is it the material entity of the absent that speaks; if truth must be revealed by digital data, where does that place the human subject as the witness?

The witness, we can conclude, is a complex figure, which ranges from an embodied identity to disembodied materiality, but as both franchises demonstrate, its definition and nature are not as simple as speaking for the Other and being heard. The nature of the witness has been challenged in relation to the way in which truth, the body and subjectivity are approached. How we come to understand the role of the human subject in conjunction with technology changes that which we define as witnessing and the witness. 


\section{Top-down or Rhizomatic}

The two franchises mobilize surveillance by addressing the post-panoptic accessibility of technology, including the horizontal spread of its use and the way in which it is employed to resist power and control. Both franchises tend to portray this extension in a negative light, criticizing the dangers of surveillance when in the hands of 'the people'. By presenting the risks of the surveillant assemblage, the two franchises convey a conflicting dialogue that envisions the advancement of surveillance as necessary and vital for the authorities, while frowning on its democratic use. Despite recognizing the post-panoptic notions of surveillance in today's society, the franchises try to return to the preferred panoptic top-down model of surveillance that places the devices in the hands of the few, watching the many.

The franchises' negative criticism of the horizontal expansion of surveillance and its synoptic and superpanoptic characteristics are revealed when the human subject manages to catch a crime on camera. The investigators then turn to that camera to give them clues to solve the crime, or use it as the witness to argue their case. Hence despite the preference for a top-down notion of surveillance, and the assertion of the risks of rhizomatic surveillance, they do acknowledge and use the evidence available via its expanding presence in and use by society. Different from the panoptic model, both franchises acknowledge that the authorities can be flawed, and that the observer can be corrupt, causing risks. While the CSI franchise uses this to further foster the neutrality of technology over the human body, including the investigative team, the Law \& Order franchise advocates surveillance to extend the human body despite its potential risks. 
This difference between the two franchises explains how one can be read as reclaiming the human subject by perfecting it, while the other as envisioning the human as subordinate and granting agency to technology.

In his post-panoptic writing, Bogard (2006) addresses the surveillant assemblage and our current access to information by arguing that our current relationship with technology is being advocated by the likes of law enforcement, corporations and the State. However Bogard states that if surveillance is about control and the police, it also has anti-police, anti-control tendencies which are immanent to its deterritorialization (Bogard, 101). As the franchises demonstrate, and as Bogard notes, the police attempt to either retain exclusive control over the information or block its use. Despite this reality, Bogard claims that the tendency of the surveillant assemblage, information networks, and power relations to develop rhizomatic connections precludes the success of exclusionary strategies of information control (Bogard, 101). Bogard is not naive to recognize that the free flow of information in the surveillant assemblage does not make its democratization necessarily beneficial. He notes that where there is power, there is also resistance and the infringing use of the technology is part of the assemblage. Thus by recognizing its democratization, one must also recognize the inevitability of its potential negative use.

The normalization of the use of surveillance technology is explained by Lyon's (2006) notion that surveillance can manage to succeed in its initial objective of selfdiscipline, if it is handled in a subtle manner. Lyon argues that entertainment can help make surveillance seem beneficial by equating pervasive monitoring with self-expression (Lyon, 14). Although his analysis refers specifically to Reality TV and panopticism, a 
similar claim can be made with respect to crime action genres and specifically to both the Law \& Order and CSI franchises in relation to the post-panoptic. In their humanist and posthumanist mobilizations of surveillance, they convey both the benefits and necessity of such devices, and suggest that those who are bothered by the privacy infringing nature of surveillance must have something to hide. They normalize and neutralize the technology, containing its risks and discrediting overt resistance to it. While acknowledging a post-panoptic world, they advocate for panoptic control.

The CSI franchise portrays technology as sexy and fun; its alluring appeal stems from the fact that the dirty images are left at the crime scene, rather than brought into the investigation process. Since both franchises convey technology as a benign force when in the hands of authorities, they normalize its use. Despite their differences, both franchises demonstrate surveillance technology as a measure for containing risks in today's society and thus their approach to its potential and use helps to diffuse critiques of surveillance technology. The impact of normalizing surveillance technology, as is a result of the two franchises, resonates with Doyle's (1998) understanding that mass media shapes the practices of other institutions, for example the justice system, and that it also reflects social and cultural shifts, including our perception of both the witness and surveillance technologies.

Referring back to Bogard, he reaffirms Jean-Francois Lyotard's notion that power in postmodernity is about access to data banks and claims that "free access to data on you, but not by you is the goal of police control of surveillance networks" (Bogard 2006, 117). What surveillance provides for the Law \& Order and the CSI franchises is a 
measure to enhance the abilities to see, to match, and to track. It speaks for the bygone and becomes necessary to fill the lack to which Peters (2001) refers. For Peters, that lack is the truth, and in the information age, with the advancement of technology, he argues that the human witness alone cannot secure conviction or acquittals. The role of surveillance hence parallels that of witnessing. Surveillance, according to Los (2006), also offers a sense of truth amid alienation and mistrust. She claims that the information age, due to the increasing accessibility of the information that is collected and the changing pace of society, leaves very little sense of trust for the human subject, or between human subjects. Surveillance thus becomes the way in which one learns about the Other.

The CSI franchise's understanding of the witness, the body and the authority invested in technology provides an apolitical approach that fails to criticize the justice system, the invasiveness of the technology it employs, or the surveillance society. The unforgiving perception of human frailties that it presents in the process of discrediting the human witness, limits the three series' potential to engage in a critique. In CSI, the manner in which the truth is 'revealed' and the body is perceived as information grants legitimacy to surveillance. However, for Law \& Order, the flaws of humanity provide for a more complex, moral and ethical narrative that recognizes human weaknesses, but also depends on the human subject to construct the truth. This is not to suggest that Law \& Order ignores surveillance technology's ability to enhance the process of witnessing, but in redeeming and retaining the human witness, it can offer a more critical view of surveillance society. However, both narratives must turn to technology. The surveillance 
literature allows for a critique of technology, while popular culture's understanding of the witness provides a reflection of surveillance technology, of the subject and of the body that allows us to question our own approach to the body, to technology, to truth and to accepting the normalization of surveillance. Whether technology extends or replaces the witness, it inevitably becomes an important part of the process, demonstrating its own vitality. Surveillance technology is validated as necessary in the quest for truth, security and justice. 


\section{Appendix}

This is a sample coding sheet used in analyzing each episode in the methodology of this paper.

\section{STEP I:}

Each episode was viewed the first time around with the following checklist and questions. The data collected from this question sheet, for each episode, was then grouped together to find common themes.

\section{Check list:}

Technology employed in each episode:

Moulds:

DNA:

Databases:

Residue Testing:

Matching bullet casings: Phone records:

Tracing objects to manufacturers:

Access to Membership Royalty records/library cards:

Gun Shot Residue:

'Blue light':

\section{Body as Information}

Stomach Content:

Dental records:

Bruises:

Residue on the body:

DNA on body/under nail:

Credit card records:

Hand/ Fingerprint:

Pictures as evidence:

Reconstructing Shots:

DNA/fingerprint on weapon:

Heat Imagers:

Time of Death/ to create a timeline:

Vasectomy/implants:

Time of Death/ to create a timeline:

Blood Splatter:

\section{Witness}

No live human subject as the witness:

Witness is a techno-witness: 
Human subject as witness- is it helpful in the solving the crime?

Is the human subject as the witness discredited by lies/motive/reputation?

Is the human subject's testimony discredited by technology?

Relationship of technology and the human subject

Detective and technology

- How does technology help the detective?

- How does the detective approach the technology? As a helpful tool or a threat?

- What role does the technology play in solving the case?

- Do the detectives turn to technology or the live subject for solving the crime?

- Do the detectives differentiate between the live subject and evidence?

Victim and technology

- Is the dead victim approached as a victim or a body?

- What information does the technology gather from the body?

- How does the information that the technology gathers from the body, help solve the crime? What does it contribute?

- Body- Does DNA or any other bodily fluids, help solve the case?

- Is the body approached separate from the technology?

Scientist and technology

- How does the scientist use the technology?

- Does the technology override the scientists own findings?

- What is the role of the scientist in solving the case?

- Aesthetically, is it the technology or the scientist that is romanticized?

Witness and technology

- Is the witness a human subject?

- Is the witness a techno-witness?

- How is the live subject as the witness treated in relation to the findings of the technology?

- Does the human subject's testimony outweigh the technologies findings?

- Does the human subject's testimony conflict with the findings of the technology?

- Does the technology help confirm the witness's testimony?

- Does the technology help fill in the gaps in the witness's experience?

- How is the human subject as a witness depicted in relation to the techno-witness? 
Witness and detective

- How does the detective/investigator treat the human subject as witness?

- What becomes the witness for the detective?

- Does the detective go back to the body? Human subject or evidence as the witness?

- Is the witness subjective/objective/ source of information?

\section{STEP II:}

Once the questions in Step I were filled out, the findings demonstrated a common theme in the relationship between technology and the body and in its role in driving the narrative and solving the crimes. The data collected could be categorized under the framework of prosthesis or replacement. Step II included the revisiting of each episode selected for the analysis to see if it is possible to categorize them as either one. What was concluded in the final stage of Step II was that not only could the episodes be distinguished as replacement or prosthesis, but each series would fall primarily under one of the frameworks and in the end, the three CSI and the two Law \& Order series were different as they consistently fit within one of the frameworks across the franchise.

\section{Prosthesis- as enhancement}

- Relationship of technology and body- how is technology enhancing human skills?

- Which skills are being enhanced by the technology?

- How is technology helping the solving of each case?

- Does the episode use technology to fix the shortcomings of the human subject as witness-to fill the gaps of what was not experienced?

- Does technology become a necessary measure taken in the investigate process, as a routine procedure, or does it become central to the solving of the crime?

\section{Replacement- replacing man with technology}

- Relationship between technology and body- does the technology solve the crime?

- Do the investigators rely on technology over the human subject as the witness? And to solve the crime?

- Does the technology replace the detectives work in solving the crime?

- Does technology gain central stage?

- How is the technology helped in discrediting the human subject as witness?

- Does the information that the technology provides, produce a different story than what the human subject provided?

- How is the human subject (victim/witness/detective) depicted? Is the way in which the human subject is depicted effect the authority/agency placed on technology? - Which experience (what the technology gathers or the human subject testifies) solves the case?

-How is the editing and camera shots of the program support the replacement of the human subject by technology? 


\section{STEP III:}

Concepts and themes that reoccurred throughout the analysis were therefore addressed within the paper (listed below are some of the findings):

- Post 9/11 and surveillance narrative with moral undertones

-Scientist's role within the narrative and cinematography

-The role of the witness as human subject versus that of the techno-witness distinguished the programs apart

-Truth ontology became a concept to address- how each series and each franchise approached truth production and whether this changed the relationship between the body and technology

- Return of the panoptic- despite its post panoptic awareness, the advocacy for top-down model of surveillance 


\section{Sources}

Badmington, Neil. (2003). Theorizing Posthumanism. Cultural Critique. 53 (Winter),1027.

Ball, Kirstie. (2006). Organization, Surveillance and the body: towards a politics of resistance. In David Lyon (Ed.), Theorizing Surveillance: The panopticon and beyond. (pp. 296-317). Portland, Oregon: Willan Publishing.

Beck, Ulrich.(1992). Risk Society: Towards a New Modernity. London: Sage.

Bernhard, Brendan (2007). 'South Beach Riot'. The New York Sun. (February 6) Website: http://www.nysun.com/article/48049.

Accessed: April $29^{\text {th }} 2007$.

Bogard, William. (2006). Surveillance assemblages and lines of flight. In David Lyon (Ed.), Theorizing Surveillance: The panopticon and beyond.(pp.97-119). Portland, Oregon: Willan Publishing.

Bogard, William. (1996). The Simulation of Surveillance: Hypercontrol in Telematic Societies. Cambridge: Cambridge University Press.

Bostrom, Nick. (2005). In Defence of Posthuman Dignity. Bioethics. Vol. 19(3), 202214.

Burfoot, Annette. (2003). Human Remains: Identity Politics in the Face of Biotechnology. Cultural Critique. 53, 47-71.

Calhoun, C. (1992). The infrastructure of modernity: Indirect relationships, information technology and social integration. In N. Smelser \& Haferkamp (Eds.), Social change and modernity (pp.205-236). Berkeley: University of California Press

Castells, Manuel. (1996).The Rise of the Network society. The Information Age: Economy, Society and Culture. Vol.1 Cambridge, MA: Oxford, UK: Blackwell.

Deleuze, Gilles and Felix Guattari. (1987). A Thousand Plateaus. Trans. Brian Massumi. Minneapolis: University of Minnesota Press.

Derrida, Jacques. (1967). Excerpt from Of Grammatology. In Charles Harrison and Paul Wood (Ed.), (1996). Art in Theory: 1900-1990 (pp. 918-923). Oxford: Blackwell.

Doyle, Aaron. (1998). Cops: Television Policing as Policing Reality. In Mark Fishman and Gray Cavender (Ed.), Entertaining Crime: Television Reality Programs (pp. 95-116). New York: Aldine de Gryter.

Dubbeld, Lynsey. (2003). Observing bodies: Camera surveillance and the significance of 
the body. Ethics and Information Technology, 5, 151-162.

Ellis, John. (2000). Seeing Things: Television in The Age of Uncertainty. London: IB Tauris.

Eschholz, Sarah, Matthew Mallard and Stacey Flynn. (2004). Images of Prime Time Justice: A Content Analysis of "NYPD Blue" and "Law \& Order". Journal of Criminal Justice and Popular Culture. School of Criminal Justice, University at Albany. 10(3), 161-180.

Ford, Henry. (1923). My Life and Work. New York: Doubleday.

Foucault, Michel. (1977). Panopticism, Discipline and Punish. New York: Vintage Books.

Gandy, Oscar. (1995). 'It's Discrimination, Stupid!". In James Brook \& Iain Boal (Eds.), Resisting the Virtual Life: The Culture and Politics of Information. (pp.35-47). San Francisco: City Lights.

Gandy, Oscar. (2006). 'Quixotics unite! Engaging in the pragmatists on rational discrimination.' In David Lyon (Ed.)Theorizing Surveillance: The panopticon and beyond (pp. 318-333) Portland, Oregon: Willan Publishing.

Gandy, Oscar. (1993). The Panoptic Sort: A Political Economy of Personal Information. Boulder: Westview Press.

Gever, Martha. (2005). The Spectacle of Crime, digitized: CSI and Social anatomy. European Journal of Cultural Studies, 8(4), 445-463; 1367-5494.

Giddens, Anthony.(2000) Global Capitalism. New York, New Press.

Goodland, Lauren. (2003). Beyond the Panopticon: Victorian Britain and the Critical Imagination. PMLA, 118(3), 539-56.

Gray, Mentor et al. (1995) Cyborgology: Constructing the Knowledge of Cybernetic Organisms. In Chris Hables Gray (Ed.), Cyborg Handbook. New York: Routledge.

Haggerty, Kevin D. (2001). Making Crime Count. Toronto; Buffalo: University of Press.

Haggerty, Kevin D. (2006). Tear down the walls: on demolishing the panopticon. In David Lyon (Ed.), Theorizing Surveillance: The panopticon and beyond (pp.2345) Portland, Oregon: Willan Publishing.

Haggerty, Kevin D. and Richard V. Ericson. (2006). The New Politics of Surveillance and Visibility. Toronto: University of Toronto Press. 
Haggerty, Kevin and Richard V. Ericson. (2000).The Surveillant Assemblage. British Journal of Sociology, 51(4).

Hanson, Allen F. (1993). Testing Testing: Social Consequences of the Examined Life. Berkeley: University of California Press.

Haraway, Donna. (1997). Modest Witness @ Second Millennium: Femaleman Meets Oncomouse: Feminism and Technoscience. New York: Routledge.

Haraway, Donna. (1991). A Cyborg Manifesto: Science, Technology and SocialistFeminism in the Late Twentieth Century. Simians, Cyborgs, and Women: The Reinvention of Nature. New York: Routledge.

Hayles, Katherine N. (2003). Afterword: The Human in the Posthuman. Cultural Critique. 53. (winter), 134-137.

Hayles, Katherine N. (1999). How we became Posthuman. Chicago \& London: The University of Chicago Press.

Heffernan, Teresa. (2003).Bovine Anxieties, Virgin Births, and the Secret of life. Cultural Critique. 53. (winter), 116-133.

Heinrick, Jeffrey. (2006). Everyone's an Expert: The CSI Effect's Negative impact on Juries. The Triple Helix. Arizona State University Press.

Iyer, Lars. (2003). The Unbearable Trauma and Witnessing in Blanchot and Levinas. Janus Head. 6(1), 37-63.

Jain, Sarah S. (1999). The Prosthetic Imagination: Enabling and Disabling the Prosthesis Tropes. Science, Technology, and Human Values. (24) 31-54.

Kurzweil, Ray. (1990). The Age of Intelligent Machines. Cambridge. Mass: MIT Press.

Los, Marina. (2006). Looking into the future: surveillance, globalization and the totalitarian potential. In David Lyon (Ed.), Theorizing Surveillance: The panopticon and beyond (pp. 69-94). Portland, Oregon: Willan Publishing.

Lyon, David and Elia Zureik. (1996). Computers, surveillance, and privacy. Minneapolis: University of Minnesota Press.

Lyon, David. (2002). Everyday Surveillance: Personal data and social classification. Information, Communication \& Society. 5(2), 242-257.

Lyon, David. (2001). Surveillance Society: Monitoring everyday life. Buckingham; Philadelphia, PA: Open University. 
Lyon, David. (2006). 9/11, Synopticon, and Scopophilia: Watching and Being Watched. In Kevin D. Haggerty and Richard V. Ericson (Eds.), The New Politics of Surveillance and Visibility. Toronto: University of Toronto Press.

Lyon, David. (1994).The Electronic Eye: the Rise of Surveillance Society. Minneapolis: University of Minnesota Press.

Lyon, David. (2006). The search for surveillance theories. In David Lyon (Ed.), Theorizing Surveillance: The panopticon and beyond (pp.3-20) Portland, Oregon: Willan Publishing.

Mann, Michael D. (2006). The "CSI Effect": Better Jurors through television and science? Buffalo Public Interest Law Journal. Berkeley: The Berkeley Press.

Mann, Steve and Jason Nolan and Barry Wellman. (2003). Sousveillance: Inventing and Using Wearable Computing Devices for Data Collection in Surveillance Environments. Surveillance \& Society. 1 (3), 331-355.

Marx, Gary, T. (1996). Electric Eye in the Sky: Some Reflections on the New Surveillance and Popular Culture. In David Lyon and Elia Zureik (Ed.), Computers, Surveillance and Privacy. Minneapolis: University of Minnesota Press.

Marx, Karl. (1867). The Fetishism of the Commodity and the Secret Thereof. Capital: A critique of Political Economy Capital (pp. 76-87). New York: International Publishers.

Mathieson, Thomas. (1997). The Viewer Society. Theoretical Criminology, 1(2).

Mathieu, Emily. (2006). Sweet Microchip Love. The Toronto Star. (February 14). A4.

Mills, Sara. (2003). Michel Foucault. London and New York: Routledge.

Moravec, Hans P. (1988). Mind Children: The future of robot and human intelligence. Cambridge, Mass.: Harvard University Press.

Mulgan, Geoffrey, J. (1991) Communication and Control: Networks and the New Economies of Communication. New York: Guilford.

Norris, Clive and Gary Armstrong. (1999). The Maximum Surveillance Society: The rise of CCTV. Oxford; New York: Berg.

Parkes, W., and Laskar, L. (Producers), \& Robinson, P.A. (Director). (1992).Sneakers [motion picture]. USA: Universal Studios 
Pepperelli, Robert. (1995). The Posthuman Condition: Consciousness Beyond the Brain. Address: www.robertpepperelli.com/posthuman.com.

Accessed: 07/01/07.

Peters, John Durham. (2001). Witnessing. Media, Culture \& Society. 23, 707-723.

Pinchevsci, Amit. (2001). Freedom from Speech (or the Silent Demand). Diacritics.3(2), 71-84.

Poster, Mark. (1990). The Mode of Information. Cambridge: Polity Press.

Price, Robert M. (1993).Representing Order: Crime, Law and Justice in the News Media. Canadian Journal of Communication. 18 (1).

Rapping, Elayne. (2003). Law and Justice as seen on TV. New York: New York University Press.

Seltzer, Mark. (1992). Bodies and Machines. New York and London: Routledge.

Simon, Bart (2003). Toward a Critique of Posthuman Futures. Cultural Critique. 53 (winter),1-9.

Staples, William G. (2000). Everyday Surveillance: Vigilance and Visibility in Postmodern Life. Lanham, MD: Rowman \& Littlefield Publishers.

Staples, William G. (1997). The Culture of Surveillance: discipline and social control in the United States. New York: St. Martin's Press.

Stiegler, Bernard. (2001). Derrida and Technology: Fidelity at the Limits of Deconstruction and the Prosthesis of Faith. In Tom Cohen (Eds.), Jacques Derrida and the Humanities. Cambridge and New York: Cambridge University Press.

Tait, Sue. (2006). Autoptic vision and the necrophilic imaginary in CSI. International journal of Cultural Studies, 9(1), 45-62.

Thacker, Eugene. (2003). Data Made Flesh Biotechnology and the discourse of the Posthuman. Cultural Critique. 53, 72-97.

Tyler, Tom R. (2006). Viewing CSI and the Threshold of Guilt: Managing Truth and Justice in Reality and Fiction. The Yale Law Journal, 1050-1085.

Van der Ploeg, Irma. (2003).Biometrics and Privacy: A note on the politics of theorizing technology. Information, Communication \& Society, 6 (1), 85-104.

Van der Ploeg, Irma. (2002). Biometrics, and the body as information: normative issues 
of the socio-technical coding of the body. In David Lyon (Ed.), Surveillance as social sorting: privacy, risks, and automated discrimination (pp.57-73). New York: Routledge.

Whitaker, Reg. (1999). The End of Privacy: How Total Surveillance Is Becoming A Reality. New York: The New York Press.

White, Emily. (2002). Forever Young. New York Times. March 10, A2.

Zaslow, J. (2002). 'A Real Reality Show', USA Weekend. 20 January. Address: http://www.usaweekend.com/02 issues/020120/020/20petersen.html. Accessed: 07/15/07. (2006). Couples implant chips to take love to a new level. CTV.ca (Feb. 16). Address:http://www.ctv.ca/servlet/ArticleNews/story/CTVNews/20060214/techn ological_love_060214/20060215?hub=Canada. Accessed: 07/05/07.

Case Study:

Law \& Order official websites

Law \& Order: www.nbc.com/Law \& Order/

Law \& Order SVU: www.nbc.com/Law_\&_Order: Special_Victims_Unit/

Law \& Order CI: www.nbc.com/Law_\&_Order: Criminal_Intent/

\section{CSI official websites}

CSI: http://www.cbs.com/primetime/csi/

CSI: Miami: http://www.cbs.com/primetime/csi_miami/

CSI: New York: http://www.cbs.com/primetime/csi_ny/

\section{Episodes}

\section{CSI}

Zuiker, A., Cannon, D. (Writers), \& Lewis, R.J. (Director). (2003). Assume Nothing. In Anthony E. Zuiker (Producer), CSI. CBS: 4-02.

Goldfinger, S. (Writer), \& Bailey, R. (Director). (2004). Bad Words. In Anthony E. Zuiker (Producer), CSI. CBS: 4-19.

Mendelsohn, C., Shankar, N. (Writers), \& Fink, K. (Director). (2004). Bloodlines. In Anthony E. Zuiker (Producer), CSI. CBS: 4-23.*

Goldfinger, S. (Writer), \& McCormick, N. (Director). (2003). Coming of Rage. In Anthony E. Zuiker (Producer), CSI. CBS: 4-10.* 
Berman, J., Lipsitz, A. (Writers), \& Beesley, M. E. (director). (2003). Eleven Angry Jurors. In Anthony E. Zuiker (Producer), CSI. CBS: 4-11.

Stahl, J. (Writer), \& Fink, K. (Director). (2004). Getting off. In Anthony E. Zuiker (Producer), CSI. CBS: 4-16.

Shankar, N., Goldfinger, S. (Writers), \& Fink, K. (Director). (2003). Homebodies. In Anthony E. Zuiker (Producer), CSI. CBS: 4-01.

Berman, J. (Writer), \& Cannon, D. (Director). (2003). Invisible Evidence. In Anthony E. Zuiker (Producer), CSI. CBS: 4-04.

Berman, J. (Writer), \& Sarafian, D. (Director). (2004). Turn of the Screws. In Anthony E. Zuiker (Producer), CSI. CBS: 4-21.

Vare, E.A. (Writer), \& Sarafian, D. (Director). (2004). XX. In Anthony E. Zuiker (Producer), CSI. CBS: 4-17.

\section{CSI: Miami}

Donahue, A. (Writer), \& Chappelle, J. (Director). (2005). 10-7. In Anthony E. Zuiker (Producer), CSI: Miami. CBS: 3-24. *

O'Brien, B. (Writer), \& Lamar, G. (Director). (2006). Backstabbers. In Anthony E. Zuiker (Producer), CSI: Miami. CBS: 5-11.*

Donahue, A. (Writer), \& Chappelle, J. (Director). (2003). Big Brother. In Anthony E. Zuiker (Producer), CSI: Miami. CBS: 2-8. *

Donahue, A. (Writer), \& Cannon, D. (Director). (2003). Blood Brothers. In Anthony E. Zuiker (Producer), CSI: Miami. CBS: 2-1. *

Davidson, B. (Writer), \& Chappelle, J. (Director). (2006). Come as you are. In Anthony E. Zuiker (Producer), CSI: Miami. CBS: 5-10.*

Devine, E. (Writer), \& Beesley, M.E. (Director). (2006). Going Going Gone. In Anthony E. Zuiker (Producer), CSI: Miami. CBS: 5-9. *

Nayar, S. (Writer), \& Chappelle, J. (Director). (2004). Innocent. In Anthony E. Zuiker (Producer), CSI: Miami. CBS: 2-24.

Davidson, B., Glassner, J. (Writers), \& Alcala, F.E. (Director). (2004). Invasion. In Anthony E. Zuiker (Producer), CSI: Miami. CBS: 2-15. *

Dube, M. (Writer), \& Gaviola, K. (Director). (2004). Money for Nothing. In Anthony E. 
Zuiker (Producer), CSI: Miami. CBS: 2-17.

McGrail, A. (Writer), \& Keller, F. (Director). (2004). Murder in a Flash. In Anthony E. Zuiker (Producer), CSI: Miami CBS: 3-3.*

Maeda, S. (Writer), \& Sarafian, D.(Director). (2004). Stalkerazzi. In Anthony E. Zuiker (Producer), CSI: Miami. CBS: 2-14.

Miller, C. (Writer), \& Correll, C. (Director). (2003). Tinder Box. In Anthony E. Zuiker (Producer), CSI: Miami. CBS. 1-22. *

Brennan, S. (Writer), \& Lautanen, S. (Director).(2003). The Best Defence. In Anthony E. Zuiker (Producer), CSI: Miami. CBS: 2-05.

Bingeman, A. L. (Writer), \& Clark, D.(Director). (2004). The Oath. In Anthony E. Zuiker (Producer), CSI: Miami. CBS: 2-20.

Devine, E. (Writer), \& Keller, F. (Director). (2004). Wannabe. In Anthony E. Zuiker (Producer), CSI: Miami. CBS: 2-18. *

Modrovich, I. (Writer), \& Clark, D. (Director). (2004). Witness to Murder. In Anthony E. Zuiker (Producer), CSI: Miami. CBS:2-12.*

\section{CSI: New York}

Zuiker, A.E. (Writer), \& Sarafian, D. (Director). (2004). Blink. In Anthony E. Zuiker (Producer), CSI: NY. CBS: 1-1.

Shelton, R. (Writer), \& Lautanen, S. (Director). (2005). Blood, Sweat and Tears. In Anthony E. Zuiker (Producer), CSI: NY. CBS: 1-14.

Reiter, Z. (Writer), \& Bray, K. (Director). (2004). Grand Master. In Anthony E. Zuiker (Producer), CSI: NY. CBS: 1-4.

Tamaro, J. (Writer), \& Sarafian, D. (Director). (2004). Night, Mother. In Anthony E. Zuiker (Producer), CSI: NY. CBS: 1-10.

Lea, T. J. (Writer), \& Von Ancken, D. (Director). (2005). On the Job. In Anthony E. Zuiker (Producer), CSI: NY. CBS: 1-21. *

Battles, W. (Writer), \& Fogle, J. A. (Director). (2006). Open and Shut. In Anthony E. Zuiker (Producer), CSI: NY. CBS: 3-06.*

Shelton, E. (Writer), \& Chappelle, J. (Director). (2005). Supply and Demand. In Anthony E. Zuiker (Producer), CSI: NY. CBS:1-20. * 
McGrail, A. (Writer), \& Barba, N. (Director). (2005). The Fall. In Anthony E. Zuiker (Producer), CSI: NY. CBS: 1-17. *

Lipsitz, A. (Writer), \& Zakrzewski, A. (Director). (2004). Three Generations are Enough. In Anthony E. Zuiker (Producer), CSI: NY. CBS: 1-8.

Talbert, E. (Writer), \& Yaitanes, G. (Director). (2005). Tri-Borough. In Anthony E. Zuiker (Producer), CSI: NY. CBS:1-11. *

Lipsitz, A. (Writer), \& Clark, D. (Director). (2005). What you see, is what you see. In Anthony E. Zuiker (Producer), CSI: NY. CBS: 1-23.*

\section{Law \& Order}

Jablonski, S. (Writer), \& Makris, C. (Director). (2002). Access Nation. In Dick Wolf (Producer), Law \& Order. NBC: 12-15. *

Zelman, A., Guggenheim, M. (Writers), \& Makris, C. (Director). (2002). American Jihad. In Dick Wolf (Producer), Law \& Order. NBC: 13-1. *

Fordes, W. N. (Writer), \& Makris, C. (Director). (2003). Bodies. In Dick Wolf (Producer), Law \& Order. NBC:14-1. *

Zelman, A. (Writer), \& Scardino, D. (Director). (2004). Can I get a Witness. In Dick Wolf (Producer), Law \& Order. NBC: 14-16. *

Sweren, R. (Writer), \& Muzio, G. (Director). (2004). City Hall. In Dick Wolf (Producer), Law \& Order. NBC: 14-14.*

Sweren, R. (Writer), \& Penn, M. (Director). (2004). C.O.D. In Dick Wolf (Producer), Law \& Order. NBC: 14-24.

Turk, C. (Writer), \& Sherin, E. (Director). (2003). Embedded. In Dick Wolf (Producer), Law \& Order. NBC: 14-8. *

Nathan, R. (Writer), \& Makris, C. (Director). (2006). Fear America. In Dick Wolf (Producer), Law \& Order. NBC: 17-4. *

Diamond, J. (Writer), \& Alexander, J. (Director). (2003). Identity. In Dick Wolf (Producer), Law \& Order. NBC: 14-6. *

Zelman, A. (Writer), \& Platt, D. (Director). (2003). Ill Conceived. In Dick Wolf (Producer), Law \& Order. NBC:14-10. 
Sweren, R. (Writer), \& Segonzac, J. (Director). (2007). Melting Pot. In Dick Wolf (Producer), Law \& Order. NBC: 17-15. *

Fordes, W. N. (Writer), \& Mitchell, M. (Director). (2004). Nowhere Man. In Dick Wolf (Producer), Law \& Order. NBC: 14-19.*

Battles, W. (Writer), \& Platt, D. (Director). (2003). Patient Zero. In Dick Wolf (Producer), Law \& Order. NBC: 14-3.*

Carcaterra, L. (Writer), \& Makris, C. (Director). (2004). Payback. In Dick Wolf (Producer), Law \& Order. NBC: 14-12.*

Wilcox, D. (Writer), \& Forney, A.W. (Director). (2006). Profiteer. In Dick Wolf (Producer), Law \& Order. NBC: 17-6. *

Levinson, C. (Writer), \& Makris, C. (Director). (2006). Public Service Homicide. In Dick Wolf (Producer), Law \& Order. NBC: 17-5. *

Finkelstein, W. (Writer), \& Quinn, J. (Director). (2001). Swept Away. In Dick Wolf (Producer), Law \& Order. NBC: 11-15. *

Nahmod, D. (Writer), \& Platt, D. (Director). (2004). Vendetta. In Dick Wolf (Producer), Law \& Order. NBC: 14-21. *

\section{Law \& Order: Special Victims Unit}

Harbinson, P. (Writer), \& Shill, S. (Director). (2004). Careless. In Dick Wolf (Producer), Law \& Order: SVU. NBC: 5-18.

Grellong, P. (Writer), \& Leto, P. (Director). (2006). Choreographed. In Dick Wolf (Producer), Law \& Order: SVU. NBC: 8-17. *

Greene, J. (Writer), \& Segonzac, J. (Director). (2003). Coerced. In Dick Wolf (Producer), Law \& Order: SVU. NBC: 5-6.

Baer, N. (Writer), \& Kotcheff, T. (Director). (2003). Control. In Dick Wolf (Producer), Law \& Order: SVU. NBC: 5-9.

Green, A. (Writer), \& Forney, A. W. (Director). (2002). Counterfeit. In Dick Wolf (Producer), Law \& Order: SVU. NBC: 3-14.*

Molina, J. (Writer), \& Zakrzewski, A. (Director). (2004). Criminal. In Dick Wolf (Producer), Law \& Order: SVU. NBC: 5-21. *

Kligman, B. (Writer), \& Segonzac, J. (Director). (2003). Escape. In Dick Wolf 
(Producer), Law \& Order: SVU. NBC: 5-11.*

Nathan, R. (Writer), \& Platt, D. (Director). (2004). Hate. In Dick Wolf (Producer), Law \& Order: SVU. NBC: 5-13.

Petersen, L. M.(Writer), \& Campanella, J. J. (Director). (2004). Head. In Dick Wolf (Producer), Law \& Order: SVU. NBC: 5-25.*

Fletcher, R. (Writer), \& Bianchi, E. (Director). (2004). Ritual. In Dick Wolf (Producer), Law \& Order: SVU. NBC: 5-14.

Green, A. (Writer), \& Platt, D. (Director). (2003). Tragedy. In Dick Wolf (Producer), Law \& Order: SVU. NBC: 5-1.

DeNoon, D. (Writer), \& Deitch, D. (Director). (2002).Waste. In Dick Wolf (Producer), Law \& Order: SVU. NBC: 4-8. *

* The asterisk indicates the episodes that are referenced within the text 